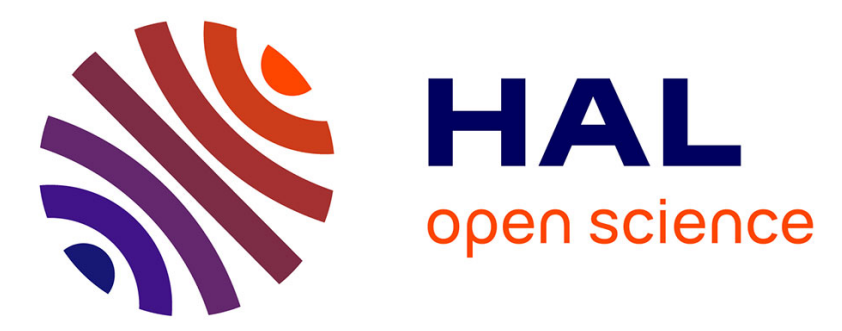

\title{
Experimental and Kinetic Modeling Study of 2-Methyl-2-Butene: Allylic Hydrocarbon Kinetics
}

Charles K. Westbrook, William J. Pitz, Marco Mehl, Pierre-Alexandre Glaude, Olivier Herbinet, Sarah Bax, Frederique Battin-Leclerc, Olivier Mathieu, Eric L. Petersen, John Bugler, et al.

\section{To cite this version:}

Charles K. Westbrook, William J. Pitz, Marco Mehl, Pierre-Alexandre Glaude, Olivier Herbinet, et al.. Experimental and Kinetic Modeling Study of 2-Methyl-2-Butene: Allylic Hydrocarbon Kinetics. Journal of Physical Chemistry A, 2015, 119 (28), pp.7462-7480. 10.1021/acs.jpca.5b00687 . hal01178244

\section{HAL Id: hal-01178244 \\ https://hal.science/hal-01178244}

Submitted on 17 Jul 2015

HAL is a multi-disciplinary open access archive for the deposit and dissemination of scientific research documents, whether they are published or not. The documents may come from teaching and research institutions in France or abroad, or from public or private research centers.
L'archive ouverte pluridisciplinaire HAL, est destinée au dépôt et à la diffusion de documents scientifiques de niveau recherche, publiés ou non, émanant des établissements d'enseignement et de recherche français ou étrangers, des laboratoires publics ou privés. 


\title{
Experimental and Kinetic Modeling Study of 2-Methyl-2-Butene: Allylic Hydrocarbon Kinetics
}

\author{
Charles K. Westbrook ${ }^{*}{ }^{1}$, William J. Pitz ${ }^{1}$, Marco Mehl ${ }^{1}$, Pierre-Alexandre Glaude ${ }^{2}$, Olivier \\ Herbinet $^{2}$, Sarah Bax ${ }^{2}$, Frederique Battin-Leclerc ${ }^{2}$, Olivier Mathieu ${ }^{3}$, Eric L. Petersen ${ }^{3}$, John \\ Bugler ${ }^{4}$, Henry J. Curran ${ }^{4}$ \\ ${ }^{1}$ Lawrence Livermore National Laboratory, Livermore, California 94550, United States \\ ${ }^{2}$ Laboratoire Réactions et Génie des Procédés, CNRS, Universite de Lorraine, Nancy, France \\ ${ }^{3}$ Department of Mechanical Engineering, Texas A\&M University, College Station, Texas 77843, \\ United States \\ ${ }^{4}$ School of Chemistry, National University of Ireland, Galway, Ireland
}

\begin{abstract}
Two experimental studies have been carried out on the oxidation of 2-methyl-2-butene, one measuring ignition delay times behind reflected shock waves in a stainless steel shock tube, and the other measuring fuel, intermediate, and product species mole fractions in a jet-stirred reactor (JSR). The shock tube ignition experiments were carried out at three different pressures, approximately 1.7, 11.2 , and $31 \mathrm{~atm}$, and at each pressure, fuel-lean $(\varphi=0.5)$, stoichiometric $(\varphi=1.0)$, and fuel-rich $(\varphi=$ 2.0) mixtures were examined, with each fuel/oxygen mixture diluted in $99 \% \mathrm{Ar}$, for initial postshock temperatures between 1330 and $1730 \mathrm{~K}$. The JSR experiments were performed at nearly atmospheric pressure ( 800 Torr), with stoichiometric fuel/oxygen mixtures with 0.01 mole fraction of 2M2B fuel, a residence time in the reactor of $1.5 \mathrm{~s}$, and mole fractions of 36 different chemical species were measured over a temperature range from 600 to $1150 \mathrm{~K}$. These JSR experiments represent the first such study reporting detailed species measurements for an unsaturated, branched hydrocarbon fuel larger than iso-butene. A detailed chemical kinetic reaction mechanism was developed to study the important reaction pathways in these experiments, with particular attention on the role played by allylic $\mathrm{C}-\mathrm{H}$ bonds and allylic pentenyl radicals. The results show that, at high temperatures, this olefinic
\end{abstract}

\footnotetext{
*E-mail: westbrookck@earthlink.net. Tel: 1-408-897-3144.
} 
fuel reacts rapidly, similar to related alkane fuels, but the pronounced thermal stability of the allylic pentenyl species inhibits low temperature reactivity, so 2M2B does not produce "cool flames" or negative temperature coefficient behavior. The connections between olefin hydrocarbon fuels, resulting allylic fuel radicals, the resulting lack of low-temperature reactivity, and the gasoline engine concept of octane sensitivity are discussed.

\section{Introduction}

Chemical kinetic simulations have grown steadily in complexity, accuracy, and impact on combustion chemistry research, taking a place with chemical theory and advanced, optical experiments as essential tools for probing practical energy systems and understanding fuel oxidation. For many years, experiments and theory generally appeared first and thus motivated subsequent kinetic modeling analysis. This sequence especially characterized development of models for combustion of small molecule fuels such as hydrogen, methane, methanol, propane, and others, where often the experimental studies had preceded kinetic models by as much as 20 or 30 years (1). More recently, improvements in kinetic modeling techniques, along with dramatic advances in computer capacities and speed have somewhat reversed this process, and kinetic reaction mechanisms for much larger and more complex fuels such as large $n$-alkanes (2), lightly branched alkanes (3), other large alkane fuels such as 2,2,4,4,6,8,8-heptamethyl nonane (4), and even biodiesel fuels (5) have appeared in advance of experimental kinetic and other studies that confirm and correct assumptions made during the kinetic model development. Kinetic models and associated sensitivity analyses can identify specific chemical reactions, reaction rates, reaction pathways, bond energies, and other thermochemical parameters that are particularly important and can accelerate development of models and general understanding of many practical combustion processes.

A particularly instructive example of this process is the study by Som et al. (6) in which uncertainties in a single reaction rate $\left(\mathrm{HO}_{2}+\mathrm{HO}_{2}=\mathrm{H}_{2} \mathrm{O}_{2}+\mathrm{O}_{2}\right)$ translate directly into uncertainties in prediction of the crank angle at which a particular engine ignites under homogeneous charge, compression ignition ( $\mathrm{HCCl}$ ) operating conditions. To chemists, such an integrated study signals a need for further analysis of that specific reaction, using whatever combination of chemical theory, optical diagnostics and other experimental techniques, and further kinetic modeling are required, and the importance of this interplay for providing improved engine power production makes chemical kinetic modeling a very applied discipline.

Kinetic modeling is particularly valuable when a combination of new experiments and kinetic modeling can address fundamental processes that have significant impacts on practical combustion problems. The present work concerns oxidation of 2-methyl-2-butene (2M2B), a small unsaturated branched hydrocarbon fuel that, to our knowledge, has not been the subject of previous kinetic 
modeling or laboratory experimental studies, although it is produced as an intermediate during the combustion of many larger hydrocarbon fuels. New experimental results of shock-tube ignition and jet-stirred reactor (JSR) oxidation of 2M2B are presented below, and a detailed chemical kinetic reaction mechanism is developed to describe the reactions involved in both sets of experiments. Overall, there are few experimental sources of data to assist in developing and testing kinetic mechanisms for $C_{5}$ and larger olefin fuels. It is also perhaps surprising that none of the past experimental or kinetic modeling papers provided intermediate species measurements for any branched unsaturated hydrocarbon fuels larger than iso-butene. The present experiments and kinetic reaction mechanism are therefore rather unique, and we hope to follow this work with similar studies of other branched, unsaturated pentenes and hexenes.

The fuel $2 \mathrm{M} 2 \mathrm{~B}$ has been selected for attention for a very particular reason. Due to the location of the $\mathrm{C}=\mathrm{C}$ double bond in the fuel molecule, nine of its ten $\mathrm{C}-\mathrm{H}$ bonds are resonantly stabilized allylic bonds, which produce allylic $\mathrm{C} 5 \mathrm{H} 9$ radicals by $\mathrm{H}$ atom abstraction from the fuel, while the remaining $\mathrm{C}-\mathrm{H}$ bond in $2 \mathrm{M} 2 \mathrm{~B}$ is vinylic and produces extremely small amounts of vinylic pentenyl radicals. This makes $2 \mathrm{M} 2 \mathrm{~B}$ an ideal fuel to study the kinetics of allylic hydrocarbon radicals and bonds and explore the role that $\mathrm{C}=\mathrm{C}$ double bonds and their associated allylic radicals play in both idealized laboratory experiments and very practical engine applications.

Finally, olefins are present in transportation fuels, including gasoline, aviation fuel, and diesel fuel in significant amounts, as much as $15-20 \%$ of gasoline, and they contribute to determining the ignition properties of those fuels, including the octane numbers that measure resistance to knocking behavior in spark-ignition engines. Smaller, branched olefins such as $2 \mathrm{M} 2 \mathrm{~B}$ are well-known to exhibit strong octane sensitivity, with fairly high research octane numbers (RON) but much smaller motored octane numbers (MON). The RON and MON for 2M2B are 97.3 and 84.7, respectively (7), and this variation persists to olefin species as large as 2,4,4-trimethyl-1-pentene $(\mathrm{C} 8 \mathrm{H} 16)$ with RON greater than 100 and MON of 86.5. Leppard (8) has discussed these octane sensitivities quite thoroughly and attributes them to a lack of low temperature reactivity in these olefins, since these sensitive fuels produce little or no negative temperature coefficient (NTC) behavior or low-temperature reactivity. Several factors have been suggested to explain this lack of low-temperature reactivity, including the presence of multiple allylic radicals that are produced by olefin fuels, and the present fuel offers an excellent opportunity to examine the reactivity of allylic radicals over a wide range of reaction temperatures.

Provided below is an overview of previous, related studies. The shock-tube experiments are discussed next, and the high temperature ignition delay time data are presented, followed by a discussion of the JSR experiments and resulting lower temperature species concentration data. Details on the chemical kinetic model are then described, with emphasis on the developments pertinent to 
simulating $2 \mathrm{M} 2 \mathrm{~B}$ combustion. This kinetic model is then compared against the shock-tube and JSR data and the chemical kinetic trends as they relate to the ignition behavior, and the species concentration profiles are discussed.

\section{Previous Related Studies}

For many years, kinetic studies of hydrocarbon species with $C=C$ double bonds were limited to ethene, propene, and the isomers of butene.(9) This attention continues to the present $(10,11)$; for example, a new, extensive review of propene oxidation kinetics $(12,13)$ summarizes much of this literature. The same review (10) also notes that, while propene is a "key intermediate in the combustion of higher alkanes $\cdots$, despite its importance, there is a lack of experimental data available in the literature for propene at low temperatures (600-1000K) and high pressures (>10 atm)." Even fewer kinetics-relevant experimental data are available for butenes, pentenes, or larger unsaturated molecules when studied as primary fuels rather than as minor intermediates in the combustion of saturated hydrocarbon fuels. Zhang et al. (14) reviewed past research on the three isomers of butene, noting that experimental and kinetic studies of $\mathrm{C} 4$ olefins are also very limited. Studies with alkene fuels with 5 or more $\mathrm{C}$ atoms that included both experiments and kinetic modeling have been carried out for the linear molecule fuel 1-pentene in rapid compression machines $(15,16)$, shock waves $(17,18)$, laminar flames (19), internal combustion engines $(20,21)$, and flow reactors (22). Experimental studies have been carried out behind reflected shock waves, stirred reactors, and rapid compression machines for 1-hexene (23-25), and for all three linear isomers of hexane (26-28). Most of these experimental studies also included either detailed kinetic modeling or kinetics-based interpretation of their results, while others $(18,28,29)$ are primarily kinetic modeling studies that provide analyses of these olefin experiments. The study of Bounaceur et al. (28) provides kinetic modeling analysis for the linear isomers of heptene in addition to the linear isomers of hexene, using RCM experimental data for the heptene isomers from Tanaka et al. (30). Much of the work on larger alkene structures has occurred in studies of methyl esters because of their importance as biodiesel fuels. Zhang et al. (31) studied the ignition kinetics of methyl nonanoate and unsaturated isomers of methyl nonenoate in a motored engine, Herbinet et al. (32) developed kinetic mechanisms for methyl decanoate and two unsaturated isomers, methyl 5-decenoate and methyl 9-decenoate, and Wang et al. (33) studied the shock tube ignition of methyl decanoate and two unsaturated isomers of methyl decenoate.

Many laboratory experiments measure integrated combustion properties such as ignition delay times or laminar burning velocities that can be very useful in testing the capabilities of proposed kinetic reaction mechanisms but do not measure concentrations of reaction intermediate chemical species. An example of this type of study of a large olefin fuel was the paper of Metcalfe et al. (34), which used a shock tube to compare the ignition of the two isomers of iso-octene, namely $2,4,4-$ 
trimethyl-1-pentene and 2,4,4-trimethyl-2-pentene, and a kinetic reaction mechanism was developed to compare the ignition of these two similar olefins. Significant insights into the effects of these slightly different fuel molecular structures on ignition properties were provided, but the lack of measurements of intermediate chemical species levels during the ignition of the two isomers limited the ability to make any strong conclusions about the capabilities of the kinetic model.

The importance of allylic $\mathrm{C}-\mathrm{H}$ bonds and allylic radicals in general is not sufficiently wellunderstood. Although the subject has been examined (35) in theoretical terms, the practical implications are sometimes misunderstood, and a thorough understanding of all of the important kinetic pathways is still evolving. For example, Minetti et al. (15) compared the low temperature ignition of $n$-pentane and 1-pentene, finding that $n$-pentane ignited much faster than 1-pentene and suggested several explanations but did not have a detailed kinetic model. Mehl et al. (36) used the RCM experiments of Minetti et al. and new high temperature shock tube experimental results of their own to compare ignition delay times of $n$-pentane and 1-pentene, concluding that $n$-pentane is faster to ignite at low temperatures because it has more NTC behavior than 1-pentene. Mehl et al. discussed the implications of their work on octane sensitivity of alkanes and alkenes, suggesting that the $\mathrm{C}=\mathrm{C}$ double bond in 1-pentene scavenges radical species at low temperatures via their addition reactions to the double bond, thereby delaying its ignition.

Several papers have discussed the concept of the "influence of the position of the double bond" in determining rates of combustion of olefins in general and ignition in particular. These studies address relative rates of combustion of isomers in a particular family of linear alkenes, most often hexenes (26-29), but also including families of linear heptanes (28), decenes (33), and methyl nonenoates (31) as well. All of these studies address reaction at low temperatures in RCM, JSR, plug flow reactors, shock tubes, and motored engines. In each of these studies, isomers in which the $C=C$ double bond are in the middle region of the fuel molecule reacted slowest, isomers with the $\mathrm{C}=\mathrm{C}$ bond located at the 2 -site in the carbon chain reacted more rapidly than those with centrally located $\mathrm{C}=\mathrm{C}$ bonds, and 1-olefins reacted fastest. These studies noted a steadily decreasing amount of lowtemperature or NTC behavior when the $\mathrm{C}=\mathrm{C}$ double bond moved toward the center of the olefin. These explanations sometimes argued that the observed behavior depended on the length of the saturated carbon atom chain available to support alkylperoxy $\left(\mathrm{RO}_{2}\right)$ radical isomerization reaction sequences discussed in commonly accepted alkane ignition mechanisms $(11,37)$, since a centrally located $\mathrm{C}=\mathrm{C}$ double bond best interrupts such an unbroken saturated chain.

One recent study of high temperature shock-tube ignition of isomers of decene by Fridlyand et al. (38) provides a significant contrast with the above isomer ignition studies. Using four isomers of decene, specifically 1-decene, cis-2-decene, cis-5-decene, and trans-5-decene as fuels, single-pulse shock tube experiments measured the concentrations of many reaction intermediate species during 
the ignition delay period for each fuel. These experiments were carried out at temperatures above 850 $\mathrm{K}$, with a residence time of about $1 \mathrm{~ms}$, and pressures of 44-60 bar. As noted in that paper, no contributions from low temperature chemistry were observed, probably because the residence time is too short, the temperatures are too high, and the reactant concentrations are too small to observe low temperature chemistry and its accompanying NTC behavior. The most important reactions were found to be the unimolecular decomposition of each decene fuel molecule and the rapid decomposition of the resonantly stabilized radicals into reactive intermediates. The main conclusion of this study by Fridlyand et al. is that the isomers with the $\mathrm{C}=\mathrm{C}$ double bond nearest the middle of the fuel (i.e., 5-decene) ignite fastest, followed by the 2-decene, with the 1-decene being slowest to ignite.

An important result of Battin-Leclerc et al. (26) describes oxidation of the linear hexenes over a rather wide temperature range, from about 500-1100 $\mathrm{K}$. In the lowest temperature range of that study, between 500 and $700 \mathrm{~K}$, experiments showed the familiar behavior of the 1-hexene isomer reacting fastest among these isomers, followed in turn by 2-hexene and then 3-hexene. However, following the end of this lowest temperature region at about $700 \mathrm{~K}$, the ordering in reactivity of the isomers becomes reversed, with the 1-hexene becoming the slowest to react and 3-hexene the fastest, and this ordering continues to the highest temperatures addressed $(1100 \mathrm{~K})$ in their study. BattinLeclerc et al. discuss the role of pressure on their results, since their experiments were carried out at atmospheric pressure, while most of the other studies, including those of Fridlyand et al., on the importance of the location of the double bond were carried out at pressures much higher than atmospheric. For example, in the studies of Vanhove et al. (27), where RCM reaction pressures were always greater than 6.5 bar, the experimental ignition delays for 1-hexene were much faster than those for 2-hexene and 3-hexene at the lowest temperatures studied $(700-750 \mathrm{~K})$, but ignition delays for all three isomers became approximately equal at about $850 \mathrm{~K}$, whereas the reactivities of the same hexene isomers in the study of Battin-Leclerc et al. were similarly fastest for 1-hexene between 500 and $650 \mathrm{~K}$ and appear to converge at about $725 \mathrm{~K}$. The study of Battin-Leclerc et al. is the only study to date in which the reversal in reaction path ordering has been observed in a single family of experiments, although it appears that the same reversal was about to occur in the Vanhove et al. study, but the limitations of the RCM approach made it impossible to extend the reaction temperature above $850 \mathrm{~K}$.

The high pressure, high temperature trends of Fridlyand et al. are in exactly the opposite direction as all of the results that focused only on the low-temperature regime. As the present experiments and modeling analysis show below, all of these apparently conflicting results and the reaction path reversal of Battin-Leclerc et al. are entirely consistent and correct, results of the profound effects of pressure and reaction temperature on the reaction pathways, especially those of the resonantly stabilized, allylic radical species formed in each family of experiments. The reaction path 
reversal first observed by Battin-Leclerc et al. (26) that occurs at about 700-725 K in their atmospheric pressure experimental conditions is moved to about $850 \mathrm{~K}$ by the higher pressure ( 8-10 bar) conditions of Vanhove et al.

Steady progress has occurred in recent years in understanding the main reaction pathways for allylic radicals. Leppard et al. $(20,21)$ used a motored CFR engine and gas chromatography to develop a detailed kinetic mechanism (39) that included most of the elementary reactions and reaction pathways that are important in low-temperature oxidation of olefin fuels. That kinetic mechanism and the accompanying discussion included the Waddington mechanism (40) additions of $\mathrm{OH}$ and then $\mathrm{O}_{2}$ to the alkene fuel, as well as $\mathrm{HO}_{2}$ addition to the fuel, leading to epoxide intermediates, reactions of $\mathrm{O}_{2}$ with the allylic alkenyl radical to produce dienes, and recombination of $\mathrm{HO}_{2}$ (and $\mathrm{CH}_{3} \mathrm{O}_{2}$ ) with allylic alkenyl radicals leading to metastable intermediates and degenerate chain branching. Leppard et al. also concluded that the low reactivity of the allylic alkenyl radicals at low temperatures was the dominant overall feature of the ignition of small molecule alkenes and discussed the role of these allylic radicals in determining octane sensitivity (8).

Subsequent studies have steadily refined these kinetic mechanisms. Vanhove et al. (27) provided a complex analysis of the hexene isomers in terms of 4 distinct reaction pathways, two of them involving addition of $\mathrm{OH}$ and $\mathrm{HO}_{2}$ to the double bond in each hexene isomer, and two more involving abstraction of $\mathrm{H}$ atoms from the hexene, followed by abstraction of another $\mathrm{H}$ atom from the allylic hexenyl radical to produce hexadiene. Mehl et al. $(29,36)$ continued the mechanism refinement and provided further insights into the impacts of olefins on RON, MON, and octane sensitivity. Improvements to the EXGAS software to extend the treatments of large olefins $(18,28)$ provided further understanding of the issues involving the role of the site of the $C=C$ double bond in the fuel molecule, and Battin-Leclerc et al. (26) summarized the current state-of-the-art with respect to kinetic modeling of the linear alkene fuels. The present study examines how the same kinetic modeling capabilities can be applied to a branched olefin.

\section{Experiments: Shock Tube}

Ignition delay times were determined behind reflected shock waves in a single-diaphragm, stainless steel shock tube. The driven section is $15.24 \mathrm{~cm}$ i.d., $4.72 \mathrm{~m}$ long, and the driver section is $7.62 \mathrm{~cm}$ i.d., 2.46-m long. A schematic of the shock-tube setup can be found from Aul et al. (41). The inside of the driven section was polished to a surface finish of $1 \mu \mathrm{m}$ root-mean-square roughness (RMS) or better. Five PCB P113A piezoelectric pressure transducers, equally spaced alongside the driven section and mounted flush with the inner surface were used along with four Fluke PM-6666 timer/counter boxes to measure the incident-wave velocities. A curve fit of these four velocities was then used to determine the incident wave speed at the end wall location. Post reflected-shock 
conditions were obtained using this extrapolated wave speed in conjunction with one-dimensional shock relations and the initial conditions at the test region. This method was proven to maintain the uncertainty in the temperature determination behind reflected shock waves $\left(T_{5}\right)$ below $10 \mathrm{~K}(42)$. Test pressure was monitored by one PCB 134A transducer located at the end wall and one Kistler 603 B1 transducer located at the sidewall, in the same plane as the observation window (Sapphire, located 16 $\mathrm{mm}$ from the end wall). Nonideal boundary layer effects measured by the change in pressure (dP/dt) behind the reflected shock wave were determined to be less than $2 \%$ per ms for all experiments. The corresponding increase in temperature for these $\mathrm{dP} / \mathrm{dt}$ levels would be less than $10 \mathrm{~K}$ for the longest ignition delay times reported herein and therefore does not have a noticeable impact on the results herein.

Experiments were performed at three different pressures (around 1.7, 11, and $31 \mathrm{~atm}$ ), and three equivalence ratios $(\varphi)$ of $0.5,1.0$, and 2.0. Polycarbonate diaphragms were used for test pressures of 1.7 and 11 atm ( 0.25 and $2 \times 1.02 \mathrm{~mm}$ thickness, respectively), while prescored aluminum diaphragms (2.29 $\mathrm{mm}$ thickness) were used for the $31 \mathrm{~atm}$ experiments. When polycarbonate diaphragms were used, a cross-shaped cutter was employed to facilitate breakage of the diaphragm and prevent diaphragm fragments from tearing off. Helium was used as the driver gas during this study.

The driven section was vacuumed down to $2 \times 10^{-5}$ Torr or better using a roughing pump and a Varian 551 Turbomolecular pump prior to every run. The pumping time between experiments was minimized using a pneumatically driven poppet valve matching the inside diameter of the driven section and allowing for a passage of $7.62 \mathrm{~cm}$ diameter between the vacuum section and the driven tube. The pressure is measured using two MKS Baratron model 626A capacitance manometers (0-10 Torr and 0-1000 Torr) and an ion gauge for high vacuums. Test mixtures were prepared manometrically in a mixing tank of $3.05 \mathrm{~m}$ length made from stainless steel tubing with a $15.24 \mathrm{~cm}$ ID. The pressure in the mixing tanks was measured using a Setra GCT-225 pressure transducer (0-17 atm). The mixing tank is connected to the vacuum system and can be pumped down to pressures below $1 \times$ $10^{-6}$ Torr. The gases (2-methyl-2-butene [Sigma-Aldrich, >99\%), $\mathrm{O}_{2}$ (Praxair, 99.999\%), and $\mathrm{Ar}$ (Acetylene Oxygen Company, 99.999\%)] were passed through a perforated stinger traversing the center of the mixing tank to allow for rapid, turbulent mixing. To further ensure homogeneity through diffusion processes, mixtures were allowed to rest for at least $12 \mathrm{~h}$ prior to making the first run. No difference in the results was observed for longer mixing times. Conditions investigated during this study are provided in Table 1.

The ignition delay time was measured using the chemiluminescence emission from the $A 2 \Sigma+$ $\rightarrow \mathrm{X} 2 \Pi$ transition of the excited-state hydroxyl radical $\left(\mathrm{OH}^{*}\right)$ using an interference filter centered at $307 \pm 10 \mathrm{~nm}$ with a Hamamatsu 1P21 photomultiplier tube. The ignition delay time is defined herein as the time between the passage of the reflected shock wave, indicated by a pressure jump in the 
signal delivered by the sidewall pressure transducer, and the intersection of lines drawn along the steepest rate-of-change of $\mathrm{OH}^{*}$ de-excitation and a horizontal line which defines the zeroconcentration level, as can be seen in Figure 1a. Time zero is defined as the time of arrival of the reflected shock wave at the sidewall measurement location. All of the data signals were recorded through a 14-bit GageScope digital oscilloscope with sampling rates of $1 \mathrm{MHz}$ or greater per channel. Note that $\mathrm{OH}^{*}$ profiles were more difficult to interpret at pressures above $1.6 \mathrm{~atm}$ under fuel rich conditions. Indeed, results typically showed a slow increase in the $\mathrm{OH}^{*}$ signal, making the ignition delay time measurements more uncertain. An example of this type of signal is provided in Figure $1 \mathrm{~b}$ and, as can be seen, the ignition delay time was taken in such a case using the highest slope after the mild increase in the $\mathrm{OH}^{*}$ signal. This definition of the ignition delay time gave consistent results with regards to the evolution of the ignition delay time with temperature and pressure at $\varphi=2$, when compared with other equivalence ratios investigated.

Table 1: Experimental conditions investigated behind reflected shock waves.

\begin{tabular}{|c|c|c|c|}
\hline Mixture composition (mole fraction) & $\begin{array}{c}\text { Equivalence } \\
\text { ratio }\end{array}$ & $\mathrm{T}_{5}(\mathrm{~K})$ & $P_{5}$ (atm) \\
\hline & & $1370-1660$ & $1.7 \pm 0.1 \mathrm{~atm}$ \\
\hline \multirow{3}{*}{$0.0006252 \mathrm{M} 2 \mathrm{~B} / 0.009375 \mathrm{O}_{2} / 0.99 \mathrm{Ar}$} & 0.5 & $1340-1550$ & $11.1 \pm 0.4 \mathrm{~atm}$ \\
\hline & & $1330-1540$ & $31.5 \pm 2.0 \mathrm{~atm}$ \\
\hline & & $1425-1670$ & $1.8 \pm 0.1 \mathrm{~atm}$ \\
\hline \multirow[t]{3}{*}{$0.00117652 \mathrm{M} 2 \mathrm{~B} / 0.0088235 \mathrm{O}_{2} / 0.99 \mathrm{Ar}$} & 1.0 & $1350-1630$ & $11.3 \pm 0.7 \mathrm{~atm}$ \\
\hline & & $1345-1575$ & $31.0 \pm 1.5 \mathrm{~atm}$ \\
\hline & & $1475-1730$ & $1.7 \pm 0.1 \mathrm{~atm}$ \\
\hline \multirow[t]{2}{*}{$0.00210532 \mathrm{M} 2 \mathrm{~B} / 0.0078947 \mathrm{O}_{2} / 0.99 \mathrm{Ar}$} & 2.0 & $1385-1635$ & $11.0 \pm 0.3 \mathrm{~atm}$ \\
\hline & & $1350-1570$ & $31.1 \pm 1.5 \mathrm{~atm}$ \\
\hline
\end{tabular}

There are essentially two sources of uncertainties in the ignition delay time: the uncertainty in the determination of the temperature behind the reflected shock wave $\left(T_{5}\right)$, and the uncertainty associated with the determination of the steepest rate of change from the $\mathrm{OH}^{*}$ profile. The temperature determination is the most important uncertainty and, as mentioned earlier, the experimental setup and method used allow for a determination of T5 within less than $10 \mathrm{~K}$. The second source of uncertainty is typically smaller than the uncertainty in the temperature, even if it is more important at high pressure for the fuel rich mixture than for the other conditions, as seen in Figure 1. Overall, the total uncertainty in $\tau_{i g n}$ reported in this study is estimated to be $10 \%$ (which also includes the temperature variation with $\mathrm{dP} / \mathrm{dt}$ ). 

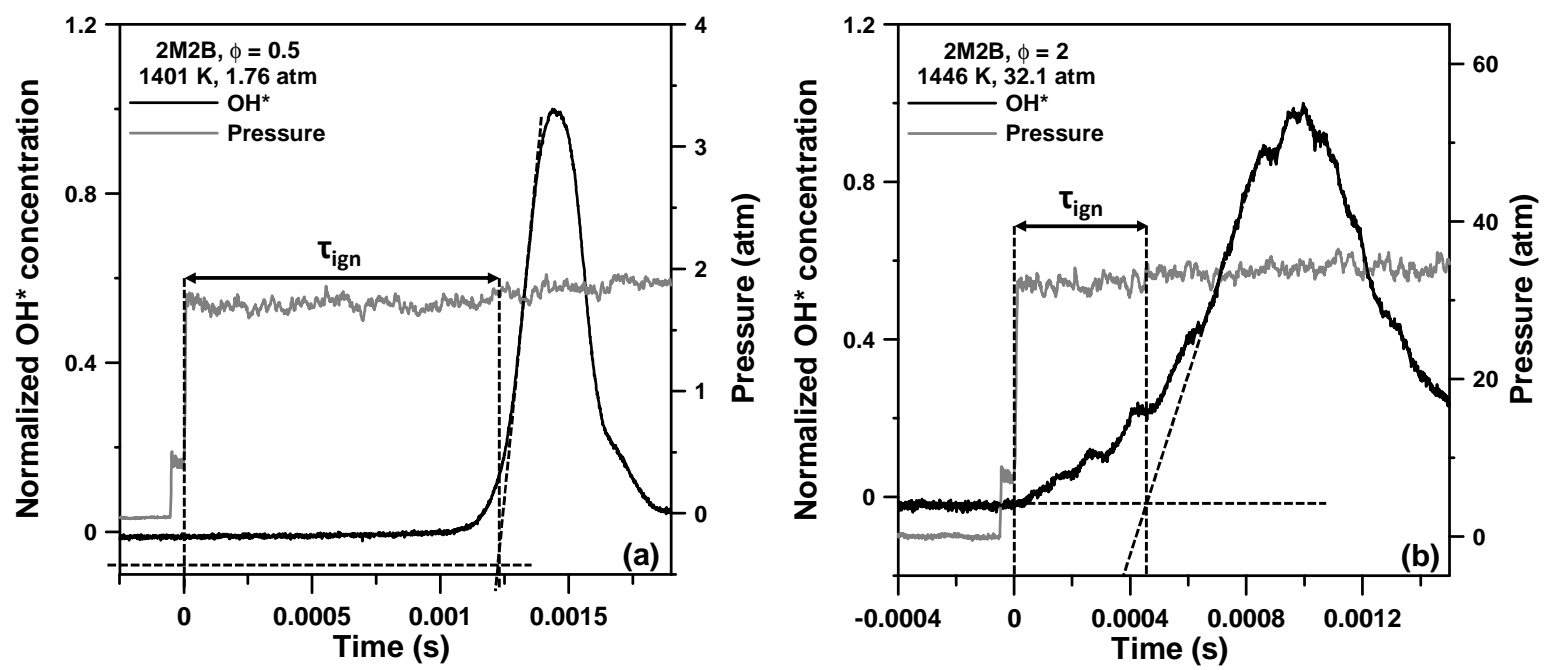

Figure 1: Examples of typical pressure and $\mathrm{OH}^{*}$ profiles and method of determination of the ignition delay time. (a) typical result for most conditions and (b) typical result for $\varphi=2.0$ above $1.6 \mathrm{~atm}$.

\section{Experimental Results: Shock Tube}

Shock-tube ignition delay time measurements were made for a total of 90 experiments, including 29 for fuel-lean $(\varphi=0.5), 30$ for stoichiometric $(\varphi=1.0)$, and 31 for fuel-rich $(\varphi=2.0)$ mixtures. All of these results are used in the following figures, and the data are available in tabular format in the Supporting Information.

\section{Equivalence Ratio Effect}

The effects of equivalence ratio on ignition delay time of 2M2B in $99 \% \mathrm{Ar}$ are shown in Figure 2 for pressures around (a) $1.7 \mathrm{~atm}$, (b) $11.2 \mathrm{~atm}$, and (c) $31 \mathrm{~atm}$. As can be seen, there is an important effect of equivalence ratio on $\tau_{i g n}$ at around $1.7 \mathrm{~atm}$. Although the apparent activation energies $\left(E_{a}\right)$ are relatively similar $(\mathrm{Ea}=53.2,52.8$, and $50.1 \mathrm{kcal} / \mathrm{mol}$ at $\varphi=0.5,1.0$ and 2.0 , respectively), one can see that an increase in the equivalence ratio by a factor 2 leads to a roughly similar increase in the ignition delay time: at around $1475 \mathrm{~K}, \tau_{\text {ign }}$ is around $1495 \mu \mathrm{s}$ for $\varphi=2.0$, and 811 and $424 \mu \mathrm{s}$ for $\varphi=$ 1.0 and 0.5 , respectively, and at $1665 \mathrm{~K}, \tau_{i g n}=54,107$, and $220 \mu \mathrm{s}$ for $\varphi=0.5,1.0$, and 2.0 , respectively. At $11 \mathrm{~atm}$ (Figure 2b), the increase in ignition delay time with the increase in the equivalence ratio is still observed. The factor of 2 seen at around 1.7 atm is still observed on the high temperature side $\left(\tau_{i g n}=88,166\right.$, and $320 \mu \mathrm{s}$ for $\varphi=0.5,1.0$, and 2.0 , respectively, at $\left.1550 \mathrm{~K}\right)$, but the increase in $\tau_{i g n}$ with $\varphi$ is reduced on the low temperature side: at $1390 \mathrm{~K}$, the ignition delay time is around 775,1270 , and $1725 \mu$ s for $\varphi=0.5,1.0$, and 2.0, respectively. Again, at this pressure condition, one can note that the activation energies are still close to each other: $E_{a}=53.5,52.5$, and $44.9 \mathrm{kcal} / \mathrm{mol}$ at $\varphi=0.5,1.0$, 
and 2.0, respectively. The low value of $44.9 \mathrm{kcal} / \mathrm{mol}$ for the activation energy of the fuel-rich mixture at $11 \mathrm{~atm}$ pressure appears to be anomalous, and as we will see below, the kinetic model provided a value of $53.5 \mathrm{kcal} / \mathrm{mol}$ under those conditions. With this larger value of $E_{a}=53.5 \mathrm{kcal} / \mathrm{mol}$, the trends for all of the activation energies are completely consistent, with mixtures for all three values of equivalence ratio showing very similar activation energies at each pressure. The fit to the experimental values of ignition delay that gave an activation energy of $44.9 \mathrm{kcal} / \mathrm{mol}$ is strongly influenced by the measured ignition delay times at the lowest temperatures, below $1400 \mathrm{~K}$, where the measured ignition delay times are longer than $1.5 \mathrm{~ms}$. While the measured and computed ignition delay times, for these mixtures at $\varphi=2.0$ and 11 bar pressure, are virtually identical between $1500 \mathrm{~K}$ and $1700 \mathrm{~K}$, where the ignition delay values are less than about $600 \mu \mathrm{s}$, at $1400 \mathrm{~K}$ the computed ignition delay time is $2.3 \mathrm{~ms}$ and the experimentally measured value is $1600 \mu \mathrm{s}$. We are confident that the computed value is more reliable at this condition than the experimental value, since experimental uncertainties often increase when the shock time ignition delay time exceed $1 \mathrm{~ms}$.

At the largest pressure investigated, around $31 \mathrm{~atm}$ (Figure 2c), the effect of equivalence ratio on ignition delay time is dramatically reduced. Ignition delay times determined at $\varphi=1.0$ and 2.0 seem nearly the same, whereas the ignition delay times at $\varphi=0.5$ are still notably shorter: at around 1540 $\mathrm{K}, \tau_{\text {ign }}=90,140$, and $160 \mu \mathrm{s}$ for $\varphi=0.5,1.0$, and 2.0 respectively. At the low temperature side, around $1390 \mathrm{~K}$, the ignition delay time is around 1475,1260 , and $835 \mu \mathrm{s}$ at $\varphi=2.0,1.0$, and 0.5 , respectively. As for the other pressure conditions, the activation energies are very close near 31 atm: $E_{a}=49.2$, 49.6 , and $50.0 \mathrm{kcal} / \mathrm{mol}$ at $\varphi=0.5,1.0$, and 2.0 , respectively.
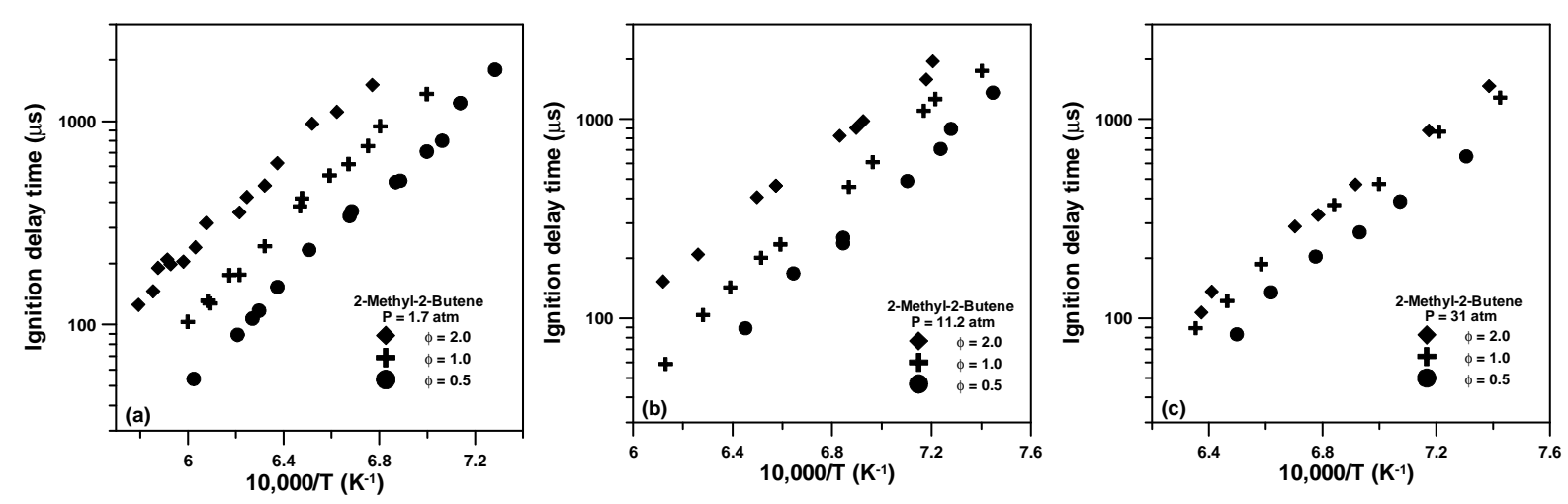

Figure 2: Effect of the equivalence ratio on the ignition delay time of 2-methyl-2-butene in $99 \% \mathrm{Ar}$ at around (a) 1.7, (b) 11.2, and (c) $31 \mathrm{~atm}$.

\section{Pressure Effect}

The effect of pressure on the ignition delay time of $2 \mathrm{M} 2 \mathrm{~B}$ is visible in Figure 3 for $\varphi=(a) 0.5$, (b) 1.0, and (c) 2.0. As can be seen, the increase in the pressure leads to a decrease in the ignition delay 
time. The amplitude of this effect is however dependent on the equivalence ratio investigated. For example, if a factor between 2.2 (at high temperature) and 2.5 (at low temperature) can be found between the ignition delay times at around 1.7 and $31 \mathrm{~atm}$ for $\varphi=0.5$, a factor between 5.5 (high temperature) and 4.5 (low temperature) is found at $\varphi=2$. Also, note that the ignition delay times at around 11 and $31 \mathrm{~atm}$ are close to each other and are dislocated from the $\tau_{i g n}$ at $1.6 \mathrm{~atm}$ for equivalence ratios of 0.5 and 1.0. At $\varphi=2.0$, however, a noticeable difference is observed between the ignition delay times of the three pressures investigated. Similar trends in ignition delay with pressure and equivalence ratio were seen in Burke et al.(13) for propene, who discussed their variations in ignition delays as determined via interactions between varying pressure-dependent reactions, including the $\mathrm{H}+\mathrm{O}_{2}(+M)=\mathrm{HO}_{2}(+M)$ reaction, which competes with the major high temperature chain branching reaction $\mathrm{H}+\mathrm{O}_{2}=\mathrm{O}+\mathrm{OH}$. These two reactions have very different activation energies ( $\sim 0.0 \mathrm{vs} 15.3 \mathrm{kcal} / \mathrm{mol})$ and an explicit pressure dependence for the $\mathrm{H}+\mathrm{O}_{2}(+\mathrm{M})$ reaction, so their complex interactions, combined with pressure dependence of many of the reactions in the 2M2B mechanism, produce the rather intricate dependences seen in Figures 2 and 3. In addition, there is some unavoidable, but relatively small, scatter in the experimental measurements. We will show below that the kinetic model reproduces these complex trends in ignition delay times seen in Figures 2 and 3 very accurately, which we feel demonstrates the capabilities of this type of detailed kinetic reaction mechanism.
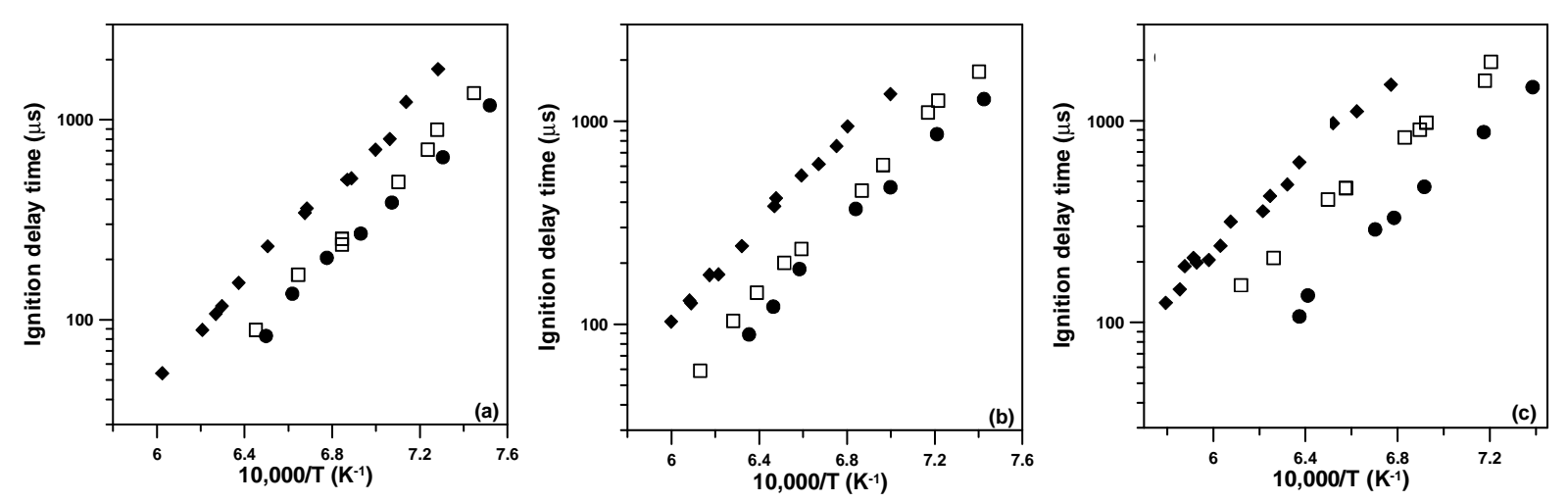

Figure 3: Effect of the pressure on the ignition delay time of 2-methyl-2-butene in $99 \% \operatorname{Ar}$ at $\varphi=(a)$ 0.5 , (b) 1.0, and (c) 2.0. show results at about $1.7 \mathrm{~atm}, \square$ show results at about $11 \mathrm{~atm}$, and the $\bullet$ show results at about $31 \mathrm{~atm}$.

Using the shock-tube data presented herein, it was possible to derive the following correlation $\left(r^{2}=0.9696\right)$, which was fit from $1330-1730 \mathrm{~K}, 1.7-31 \mathrm{~atm}$, and $\varphi$ from 0.5 to 1.0 :

$$
\tau_{\text {ign }}(\mu s)=3.57 .10^{-5} \times \varphi^{0.81} \times P^{-0.40} \times \exp \left(50.3(\mathrm{kcal} / \mathrm{mol}) / R T_{5}\right)
$$


Note the small dependence of $\tau_{i g n}$ on pressure for 2M2B (i.e., P-0.40), a "pressure exponent" of -0.40 , compared to real gasoline fuels with a pressure exponent of $-1.06(43)$ (i.e., $P-1.06$ ) or several gasoline surrogates with pressure exponents of $-0.64(44)$ and $-0.96(43)$ and alkanes such as $n$-heptane with a pressure exponent of $-1.64(43)$. This feature makes $2 \mathrm{M} 2 \mathrm{~B}$ an interesting component to limit knock in boosted gasoline engines, where the in-cylinder pressure is higher than in naturally aspirated engines.

Yahyaoui et al. $(23,24,45)$ studied shock tube ignition of 1-hexene over a range of pressures from 0.2 to $1.0 \mathrm{MPa}$, with similar fuel mole fractions, dilutions, and equivalence ratios. Although they did not report a pressure exponent from these experiments, results collected from their three papers were used to determine a pressure exponent of -0.30 , a value which, like that of $2 \mathrm{M} 2 \mathrm{~B}$, is much smaller than the pressure exponent for the alkanes and gasoline surrogates noted above. This feature may be common to other unsaturated hydrocarbon fuels and deserves further study to see if perhaps this feature may be related to the higher octane sensitivity of olefins, relative to the much lower octane sensitivities of alkane fuels.

\section{Experiments: Jet-Stirred Reactor}

Experiments were performed using a spherical fused silica jet-stirred reactor (volume $=95$ $\mathrm{cm}^{3}$ ), operating at constant temperature and pressure. Stirring is achieved by four turbulent jets from nozzles connected to an injection cross located at the center of the sphere. This ensures homogeneity in concentration inside the reactor and makes this type of reactor well-adapted for a wide-range of gas-phase kinetic studies (46) with a limited effect of possible wall reactions (47). To ensure thermal homogeneity inside the vessel, the reactor is preceded by an annular preheating zone in which the temperature of the gases is progressively increased up to the reactor temperature. Gas mixture residence time inside the annular preheater is very short compared to its residence time inside the reactor (a few percent). Both the spherical reactor and the annular preheating zone are heated by resistances rolled up around their walls. Due to a high dilution, the temperature gradients inside the reactor are always kept lower than $5 \mathrm{~K}$. Temperature control and measurements were made with type $\mathrm{K}$ thermocouples (reading error of $\pm 2 \mathrm{~K}$ ).

Experiments were performed under a constant pressure of 1.06 bar (800 Torr), at a residence time of $1.5 \pm 0.1 \mathrm{~s}$, at temperatures ranging from $600-1100 \mathrm{~K}$, and for stoichiometric conditions. Some experiments were performed at temperatures as low as $500 \mathrm{~K}$, but little reactivity was observed below $700 \mathrm{~K}$. Helium was used as diluent and the study was performed with a fuel mole fraction of 0.01 . The 2-methyl-2-butene, helium and oxygen were provided by Sigma-Aldrich (purity $299.0 \%$ ) and Messer (purity of $99.999 \%$ for $\mathrm{He}$ and of 99.995 for $\mathrm{O}_{2}$ ), respectively. Concerning the determination of 
equivalence ratios, inlet fuel mole fractions, and residence times, note that the main error is due to the precision in the gas and liquid flow measurements (using Bronkhorst High-Tech Mass Flow Controllers for gases and a Coriolis Flow Controller for the fuel) with an error of about 0.5 and $1 \%$ in flow rates, respectively.

The products leaving the reactors were analyzed online by gas chromatography via a heated transfer line between the reactor outlet and the chromatograph sampling valves which were also heated $(T=423 \mathrm{~K})$. Three gas chromatographs were used for the quantification of the different compounds. The first gas chromatograph, with helium as the carrier gas, was equipped with a Carbosphere packed column, a thermal conductivity detector (TCD), and a flame ionization detector (FID). This apparatus was used for the quantification of $\mathrm{O}_{2}, \mathrm{CO}$, and $\mathrm{CO}_{2}$. The use of helium was beneficial for the quantification of oxygen (very high sensitivity), but large amounts of helium limit the detection of hydrogen which could not be quantified during this study. The second gas chromatograph, with helium as the carrier gas, was fitted with a PlotQ capillary column and a FID and was used for the quantification of $\mathrm{C}_{1}-\mathrm{C}_{5}$ hydrocarbons and small oxygenated compounds. The third gas chromatograph was similar except that it had a HP-1 capillary column for the detection of species with at least 6 carbon atoms like benzene and toluene.

Identification and calibration of gaseous species (i.e., $\mathrm{O}_{2}, \mathrm{CO}, \mathrm{CO}_{2}$, and $\mathrm{C}_{1}-\mathrm{C}_{4}$ hydrocarbons) were performed by injecting gaseous standards provided by Messer and Air Liquide. Identification of other species used a fourth gas chromatograph coupled with a mass spectrometer (GC-MS) operating under the same conditions as the other gas chromatographs (PlotQ and HP-1) enabling direct comparison of both chromatograms. Mass spectra of all detected reaction products were included in the spectra database "NIST 08" (48). Calibration was performed by injecting known amounts of the pure substances when available, otherwise the method of effective carbon number (49) was used (species with the same number of carbon atoms and functional groups were assumed to have the same response in the FID). Among products known as important for hydrocarbon oxidation, only hydrogen, water, and formaldehyde were not quantified, but the presence of the last two of these can be identified in GC-MS analyses. Calculated relative uncertainties on species quantifications were about $\pm 5 \%$ for species directly calibrated using standards $\left(\mathrm{O}_{2}, \mathrm{C}_{1}-\mathrm{C}_{4}\right.$ hydrocarbons $)$ and about $\pm 10 \%$ for analysis of species calibrated with the effective carbon number method. Detection threshold is better than $1 \mathrm{ppm}$ for hydrocarbons and $100 \mathrm{ppm}$ for $\mathrm{CO}$ and $\mathrm{CO}_{2}$ quantified by TCD.

\section{Experimental Results: Jet-Stirred Reactor}

Many, but not all, of the experimental results obtained in the JSR are presented as symbols in Figures 4-6, and all of the experimental measurements are summarized in the Supporting Information in tabular format. These figures show that 2-methyl-2-butene starts to react at about $700 \mathrm{~K}$, with little 
reactivity observed at lower temperatures. Among the $C_{1}-C_{2}$ hydrocarbons produced, methane, ethene, $\mathrm{CO}$, and $\mathrm{CO}_{2}$ are formed in large amounts above $1000 \mathrm{ppm}$. Many larger hydrocarbons were detected and measured, including more than $1000 \mathrm{ppm}$ of 2-methyl-1,3-butadiene (isoprene, denoted as $\mathrm{i} 5 \mathrm{H} 8$ ), and lower but still significant amounts of ethane, acetylene, propene, and iso-butene. Oxygenated intermediate products, particularly acetone, acetaldehyde, methanol, acrolein $\left(\mathrm{C}_{2} \mathrm{H}_{3} \mathrm{CHO}\right)$, and methacrolein $\left(\mathrm{iC}_{3} \mathrm{H}_{5} \mathrm{CHO}\right)$, were measured at levels above $100 \mathrm{ppm}$, and smaller levels of other hydrocarbon and oxygenated hydrocarbon species were detected. In Figure 5, the species name "2M2Butenal" signifies "2-methyl-2-butenal", and "2M3B2-one" signifies "2-methyl-3-buten-2-one". In Figure 6, "2,2,3-TMO" represents "2,2,3-trimethyl oxirane", a $C_{5}$ cyclic ether. This broad variety of chemical species and the reaction pathways by which they are produced and consumed over a wide range of reaction temperatures, together with the ignition delay times from the shock tube experiments described above, form the body of data that was used to develop and test the present chemical kinetic reaction mechanism for 2M2B.
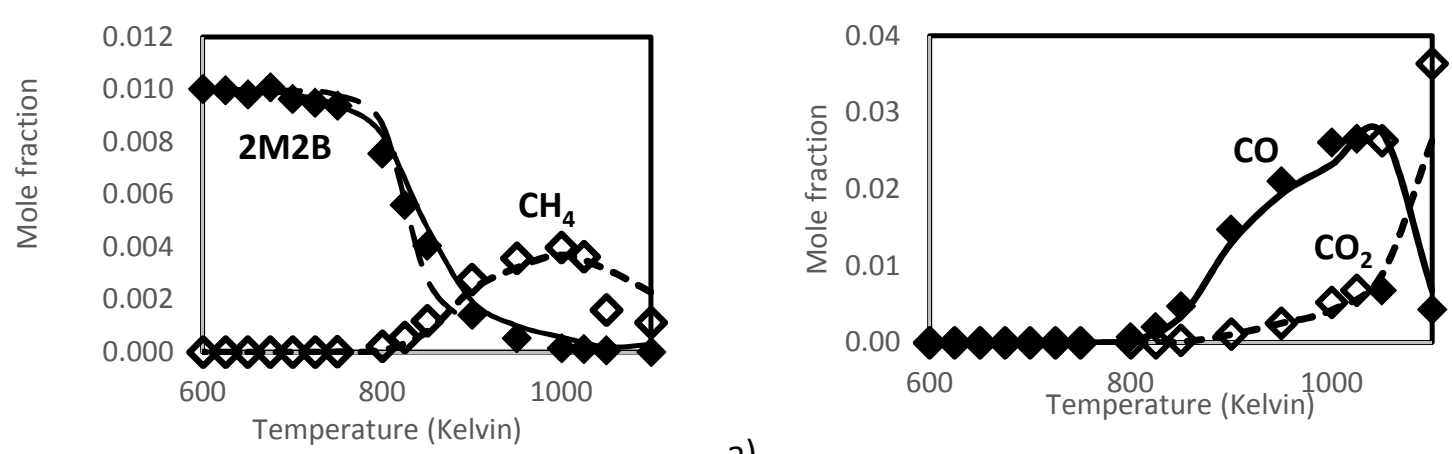

a)

b)
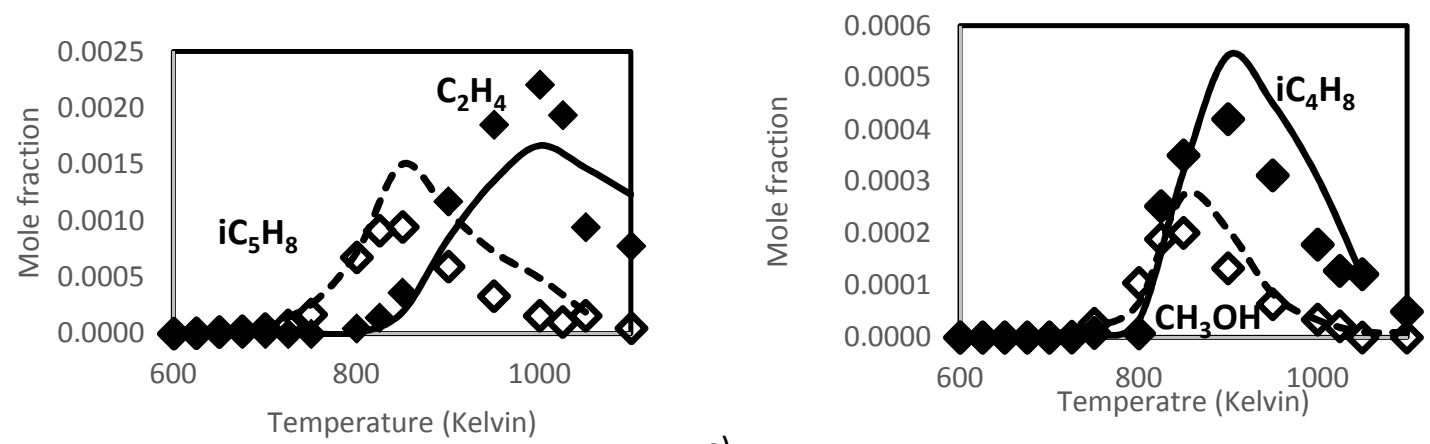

c)

d)

Figure 4: Experimentally measured mole fractions (symbols) and computed values (lines) at a range of temperatures in a jet-stirred reactor. Solid lines and filled symbols show one species in each plot, dashed lines and unfilled symbols show the second species in each figure and in Figures 5 and 6 . Long dashed line in (a) shows fuel mole fractions computed by a preliminary EXGAS mechanism (56). 

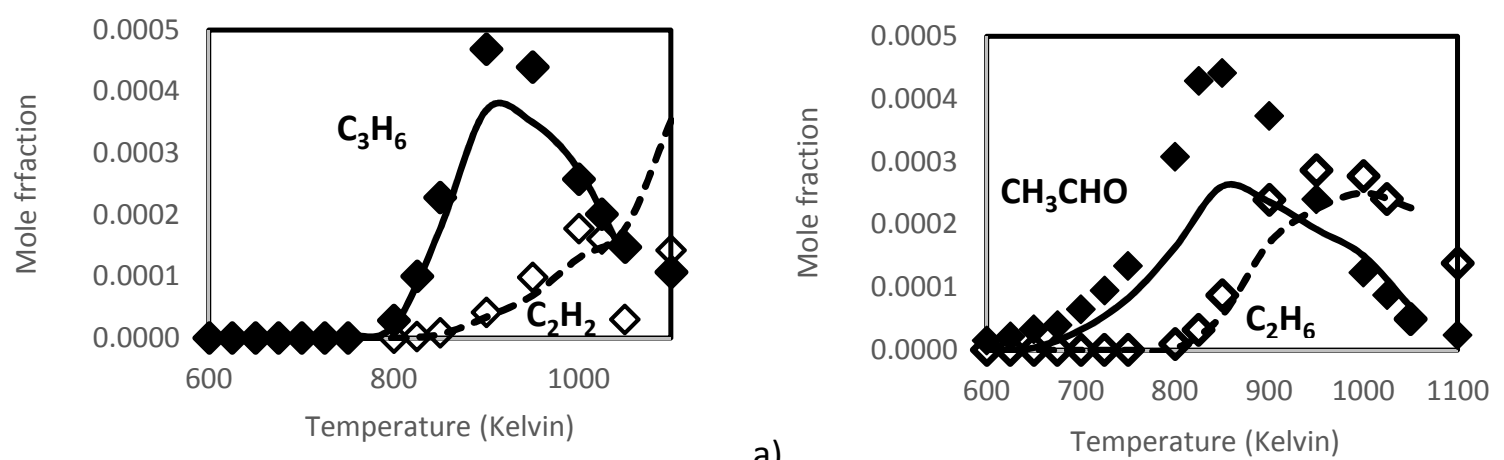

a)

b)
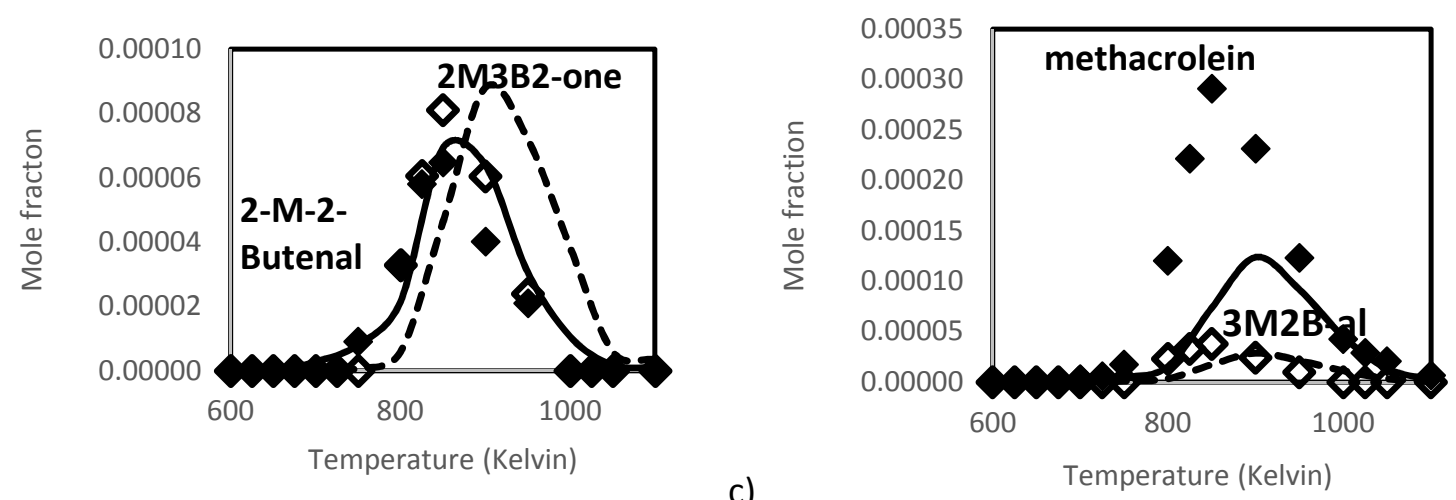

Figure 5: measured mole fractions (symbols) and computed values (lines) at a range of temperatures in a jet-stirred reactor.
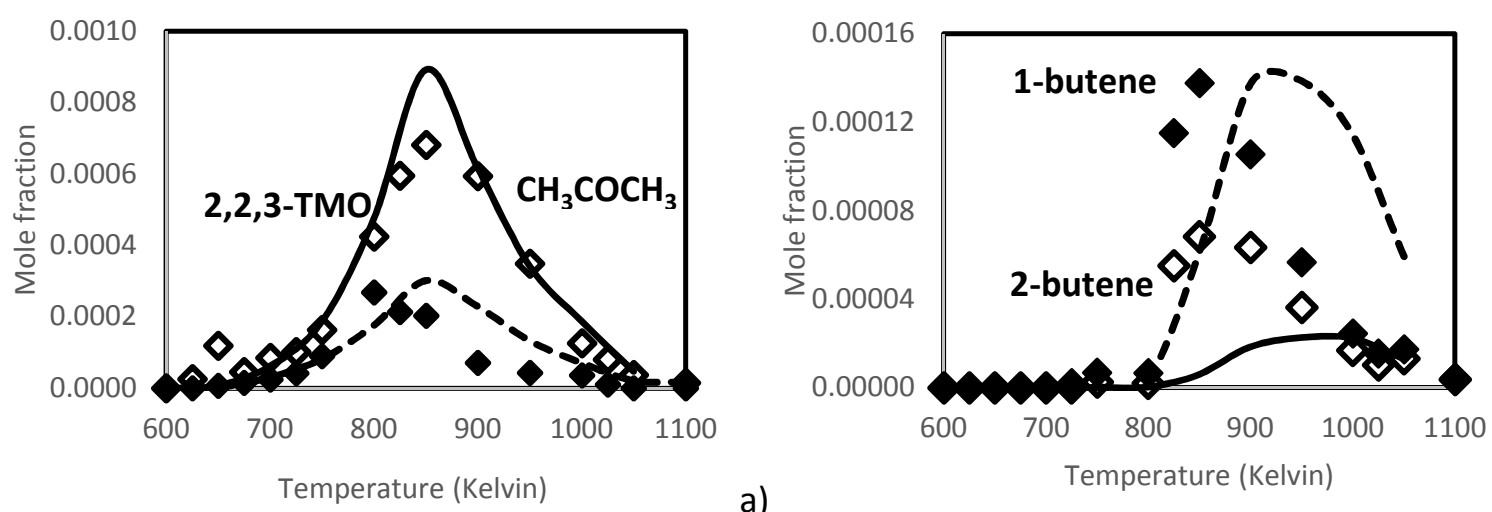

b)

Figure 6: Experimentally measured mole fractions (symbols) and computed values (lines) at a range of temperatures in a jet-stirred reactor. The solid lines and filled symbols in these plots refer to 2,2,3-trimethyl oxirane and 1-butene. 


\section{Chemical Kinetic Reaction Mechanism}

The fuel used in the present study is 2-methyl 2-butene (2M2B) as shown in Figure 7, where the lower case letters "a", " $b$ ", "c $c$ ", and "d" indicate the names of carbon sites in our naming system. Allylic sites have been marked in red. The name of the carbon is transferred to the $\mathrm{H}$ atoms connected to it, thus there are 6 structurally indistinguishable $\mathrm{H}$ atoms at the primary allylic sites labeled "a", 3 more identical $\mathrm{H}$ atoms bonded at the primary allylic " $\mathrm{d}$ " sites, and a single $\mathrm{H}$ atom bonded at the secondary vinylic site " $c$ ". Because of the large bond energy of the $\mathrm{H}$ atom connected to the vinylic site, virtually all of the $\mathrm{H}$ atom abstraction reactions occur at the allylic $\mathrm{C}-\mathrm{H}$ bonds. The same labeling system is used to designate the position of double bonds, substitutions, and radical sites. 2-Methyl-2butene can be indicated as $\mathrm{bC} 5 \mathrm{H} 10$, indicating that the $\mathrm{C}=\mathrm{C}$ double bond is at the $\mathrm{b}$ site shown in Figure 7. In our notation, 2-methyl-1-butene is named $\mathrm{aC}_{5} \mathrm{H}_{10}$ and $\mathrm{CC}_{5} \mathrm{H}_{10}$ is 3-methyl-1-butene. The present fuel $\mathrm{bC}_{5} \mathrm{H}_{10}(2 \mathrm{M} 2 \mathrm{~B})$ is particularly interesting, even among the five isomers of pentene, by having all 9 of its "abstractable" $\mathrm{H}$ atoms bonded at allylic sites in the molecule, as well as a single vinylic $\mathrm{C}-\mathrm{H}$ bond.

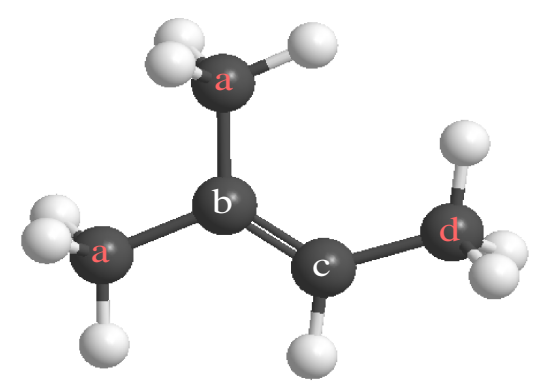

Figure 7. Schematic of fuel molecule, 2-methyl 2-butene $\left(\mathrm{bC}_{5} \mathrm{H}_{10}\right)$.

The kinetic mechanism for $2 \mathrm{M} 2 \mathrm{~B}$ was developed by combining past and ongoing work on detailed kinetic reaction mechanisms for combustion of pentanes, hexanes, and their corresponding olefins. Our past kinetic models $(2,37,50-55)$, primarily for alkane hydrocarbon fuels, included simplified mechanisms for linear and branched $C_{5}$ and other olefins, so the present work required a considerable development of the kinetic mechanism for branched pentene isomers. The core $C_{1}-C_{4}$ mechanism is the Aramco Mech1.3 (56) developed at the National University of Ireland, Galway. New experimental and kinetic modeling by Bugler et al. $(51,52)$ on $\mathrm{C}_{5} \mathrm{H}_{12}$ isomers contributed substantially to the present work, and application of the EXGAS mechanism development software with its recent upgrades specifically to address olefin mechanisms (28) by Glaude (57) helped considerably at identifying the important reaction pathways for $2 \mathrm{M} 2 \mathrm{~B}$. Many of the key reactions in both the core mechanism (56) and the specific $2 \mathrm{M} 2 \mathrm{~B}$ reaction mechanism involve changes in the number of species 
and other possible pressure dependence, and these reaction rates are treated by Troe fits or by using PLOG fits to these rates, most often at a series of pressures of $0.01,0.1,1.0,10.0$, and 100.0 bar pressures with formats prescribed by the Chemkin Pro (58) kinetic modeling software. These are all evident in the kinetics input file, which is included in the Supporting Information.

\section{Reactions Specific to 2-Methyl 2-Butene fuel}

Reactions of $2 \mathrm{M} 2 \mathrm{~B}$ fall into five general classes. These include the same types of reactions as those for any type of hydrocarbon fuel, including (a) $\mathrm{H}$ atom abstraction reactions from the fuel by small radical species, and (b) unimolecular decomposition of the fuel into two radical species. However, oxidation mechanisms for olefins are more complex than those for alkanes $(26,27,29)$ because radical addition reactions to the double bond provide other important reaction pathways. Such addition reactions, particularly of $(c) \mathrm{H},(d) \mathrm{OH}$, and (e) $\mathrm{HO}_{2}$ radicals are usually very important for unsaturated fuels and lead to product species distributions that are somewhat unique to olefin fuel consumption. We have not included addition reactions of other radical species with the fuel, due to their relatively low concentrations under the present conditions, but further reaction pathways can be added if a specific application requires such additional reaction pathways. Reaction rates were adopted initially from previous related studies of linear pentenes and hexenes $(11,18,29)$ and then modified within sensible ranges in order to best reproduce the experimentally measured shock tube ignition delay times and the stirred reactory intermediate species mole fractions, as described below. Further details can be obtained from the final mechanism provided as Supporting Information.

Given the difference between allylic and vinylic $\mathrm{C}-\mathrm{H}$ bond strengths ( $89 \mathrm{vs} \sim 108 \mathrm{kcal} / \mathrm{mol})$, we do not include $\mathrm{H}$ atom abstractions from the vinylic site in this study, as it is unlikely to influence the rate and major products of $2 \mathrm{M} 2 \mathrm{~B}$ combustion, although abstractions from the vinylic $\mathrm{c}$ site could be added if needed for particular applications. Two distinct allylic pentenyl radicals are produced via $\mathrm{H}$ atom abstraction from $2 \mathrm{M} 2 \mathrm{~B}\left(\mathrm{bC}_{5} \mathrm{H}_{10}\right)$ :

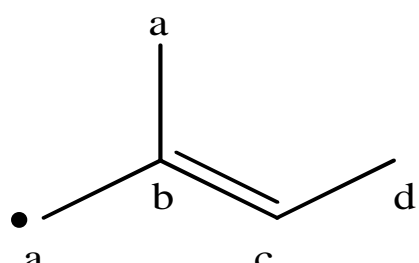

$\mathrm{bC}_{5} \mathrm{H}_{9}-\mathrm{a}$

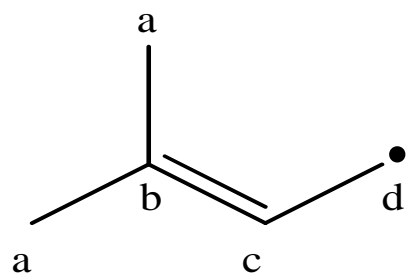

$\mathrm{bC}_{5} \mathrm{H}_{9}-\mathrm{d}$

where the letter following the bC5H9 name indicates the site of that missing $\mathrm{H}$ atom. Both of these allylic pentenyl radicals are resonantly stabilized and therefore relatively stable against thermal decomposition at low and intermediate temperatures. Their decomposition reaction activation 
energies are high, above $50 \mathrm{kcal} / \mathrm{mol}$, especially when compared with rates of thermal decomposition of alkyl or other nonallylic radicals ( $E a \simeq 35 \mathrm{kcal} / \mathrm{mol}$ ). Each of these two resonance-stabilized allylic pentenyl radicals from $2 \mathrm{M} 2 \mathrm{~B}$ has another equivalent mesomeric form which can also be produced via $\mathrm{H}$ atom abstraction from $\mathrm{aC}_{5} \mathrm{H}_{10}$ (2-methyl-1-butene) or from $\mathrm{CC}_{5} \mathrm{H}_{10}$ (3-methyl-1-butene), respectively, as shown:

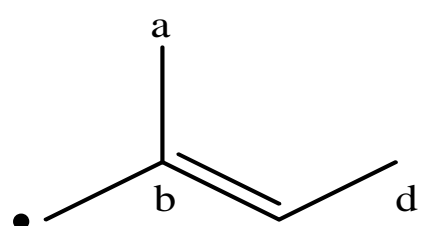

a

$$
<=>
$$

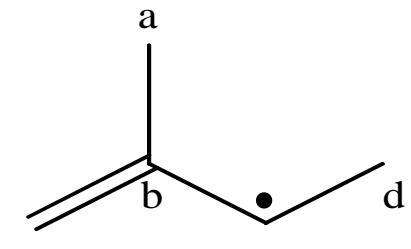

a

c

and similarly for the resonantly stabilized equivalent forms bC5H9-d and cC5H9-b:

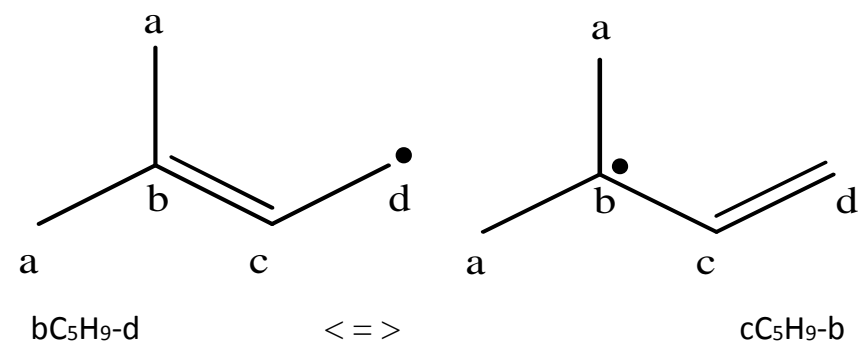

In the present mechanism, we treat each pair of equivalent allylic mesomeric forms as one species, but each radical can participate in subsequent reactions in the form of either equivalent allylic pentenyl radical. Each pair of these mesomeric forms are the two Lewis structures of that radical species. Since the $\mathrm{CC}_{5} \mathrm{H}_{9}-\mathrm{b}$ radical is a primary product of $\mathrm{cC}_{5} \mathrm{H}_{10}(3 \mathrm{M} 1 \mathrm{~B})$ and $\mathrm{aC}_{5} \mathrm{H}_{9}-\mathrm{c}$ is a primary product of $\mathrm{aC}_{5} \mathrm{H}_{10}(2 \mathrm{M} 1 \mathrm{~B})$, the reaction mechanisms of all three branched olefins of 2-methylbutane $\left(\mathrm{iC}_{5} \mathrm{H}_{12}\right)$ are kinetically interconnected via their common alkenyl species. For clarity, we use the species name $\mathrm{aC}_{5} \mathrm{H}_{9}-\mathrm{c}$ to represent both of the $\mathrm{aC}_{5} \mathrm{H}_{9}-\mathrm{c}$ and $\mathrm{bC}_{5} \mathrm{H}_{9}$-a forms, and we use $\mathrm{CC}_{5} \mathrm{H}_{9}-\mathrm{b}$ to represent both the $\mathrm{CC}_{5} \mathrm{H}_{9}-\mathrm{b}$ and $\mathrm{bC}_{5} \mathrm{H}_{9}$-d radicals. This nomenclature will facilitate our future plans to extend the present mechanism to include oxidation of the other 2-methyl butene isomers. As we show below, radical addition reactions to the $\mathrm{bC}_{5} \mathrm{H}_{9}$-a radical and the coexisting isomeric delocalized alkenyl radical $\mathrm{aC}_{5} \mathrm{H}_{9}-\mathrm{c}$, and similarly for the $\mathrm{bC}_{5} \mathrm{H}_{9}-\mathrm{d} / \mathrm{cC}_{5} \mathrm{H}_{9}-\mathrm{b}$ pair, can lead to different, quite distinct product species. Intermediate product species of both reaction pathways can be measured in the JSR experiments and must be considered separately in the chemical kinetic reaction mechanism. 
Modeling analysis of $\mathrm{H}$ atom abstraction reactions from 2M2B is simplified because all 9 such primary allylic $\mathrm{C}-\mathrm{H}$ bonds have the same energy $(\sim 88.4 \mathrm{kcal} / \mathrm{mol})$, so we assume that $\mathrm{H}$ atom abstraction reaction rates by each type of abstracting radical (i.e., $\mathrm{H}, \mathrm{O}, \mathrm{OH}, \mathrm{CH}_{3}, \mathrm{HO}_{2}, \mathrm{CH}_{3} \mathrm{O}$, and $\mathrm{CH}_{3} \mathrm{O}_{2}$ ) are the same per allylic methyl radical group. Therefore, production rates of $\mathrm{bC}_{5} \mathrm{H}_{9}-\mathrm{a}\left(\mathrm{aC}_{5} \mathrm{H}_{9}-\mathrm{c}\right)$ allylic pentenyl radicals from $\mathrm{H}$ atom abstraction reactions are exactly twice the rate of production of $\mathrm{bC}_{5} \mathrm{H}_{9}$ $d\left(\mathrm{CC}_{5} \mathrm{H}_{9}-\mathrm{b}\right)$ radicals, because $2 \mathrm{M} 2 \mathrm{~B}$ has two identical methyl radicals with a sites and one such methyl radical with " $\mathrm{d}$ " sites. We did not include in the reaction mechanism $\mathrm{H}$ atom abstractions from the fuel by any of the $\mathrm{C}_{5} \mathrm{H}_{9}$ allylic radicals.

Unimolecular decomposition reactions of $2 \mathrm{M} 2 \mathrm{~B}$ are included in the reaction mechanism, breaking either a $\mathrm{C}-\mathrm{C}$ or $\mathrm{C}-\mathrm{H}$ bond. However, due to the presence of the $\mathrm{C}=\mathrm{C}$ double bond, all of the other neighboring $\mathrm{C}-\mathrm{C}$ bond energies are quite large $(\sim 90-100 \mathrm{kcal} / \mathrm{mol})$, so these fuel decompositions are slow in both high- and low-temperature regimes. Decomposition reactions of $2 \mathrm{M} 2 \mathrm{~B}$ to an $\mathrm{H}$ atom and either of the two possible allylic pentenyl radicals are included in the mechanism, but these reactions contribute primarily in the recombination direction at low and intermediate temperatures, removing hydrogen atoms from the reactive mixture. In the shock tube experiments, temperatures are high enough that unimolecular decomposition of the fuel to allylic pentenyl radicals and $\mathrm{H}$ atoms provide initiation to $2 \mathrm{M} 2 \mathrm{~B}$ reaction. At low and intermediate temperatures, in the absence of rapid unimolecular decomposition reactions of $\mathrm{bC}_{5} \mathrm{H}_{10}$, reaction initiation takes place via reactions:

$\mathrm{bC}_{5} \mathrm{H}_{10}+\mathrm{O}_{2}=\mathrm{bC}_{5} \mathrm{H}_{9}-\mathrm{a}+\mathrm{HO}_{2}=\mathrm{aC}_{5} \mathrm{H}_{9}-\mathrm{c}+\mathrm{HO}_{2}$

$\mathrm{bC}_{5} \mathrm{H}_{10}+\mathrm{O}_{2}=\mathrm{bC}_{5} \mathrm{H}_{9}-\mathrm{d}+\mathrm{HO}_{2}=\mathrm{cC}_{5} \mathrm{H}_{9}-\mathrm{b}+\mathrm{HO}_{2}$

where the pairs of allylic alkenyl radicals are noted. No molecular elimination reactions are possible for $\mathrm{bC}_{5} \mathrm{H}_{10}$, although it can undergo a 4-membered ring rearrangement to 2-methyl-1-butene. This was not included since it would have only a very small effect on the results due to its high activation energy of about $60 \mathrm{kcal} / \mathrm{mol}$, based on the analogous 4-membered ring species in MTBE (59).

Other reactions of $2 \mathrm{M} 2 \mathrm{~B}$ fuel involve addition of radicals to the $\mathrm{C}=\mathrm{C}$ double bond and subsequent reactions of the adduct radical species. Such radical additions to the fuel molecule are not possible for alkane fuels. Measurements of several oxygenated species from low and intermediate temperature JSR experiments show that addition of $\mathrm{OH}$ and $\mathrm{HO} 2$ to the fuel are important parts of the reaction mechanism. These results are shown schematically in Figure 8 (panels a and b), showing addition of $\mathrm{OH}$ and $\mathrm{HO} 2$ to the $2 \mathrm{M} 2 \mathrm{~B}$ fuel and their major intermediate products. Addition of $\mathrm{H}$ to the fuel is also important, producing two alkyl radicals of $\mathrm{iC} 5 \mathrm{H} 12$, in this case, bC5H11 and cC5H11. At high temperatures, these $\mathrm{C} 5 \mathrm{H} 11$ alkyl radicals rapidly decompose via $\beta$-scission, producing methyl radicals 
and a butene if the decomposition breaks a $\mathrm{C}-\mathrm{C}$ bond, or back to $\mathrm{H}+\mathrm{C} 5 \mathrm{H} 10$, where any of the three 2-methylbutene isomers can be produced, depending on which alkyl radical was produced from the addition reaction. This process again mixes the species distributions of the three isomers of 2-methyl butene.

Another radical addition process to $2 \mathrm{M} 2 \mathrm{~B}$ is the Waddington mechanism (40), where $\mathrm{OH}$ adds to the $\mathrm{C}=\mathrm{C}$ double bond, followed by addition of molecular $\mathrm{O}_{2}$ to the remaining radical site. The $\mathrm{C}-\mathrm{O}-$ $\mathrm{O}$ - then abstracts the $\mathrm{H}$ from the $\mathrm{O}-\mathrm{H}$, followed by a concerted $\mathrm{C}-\mathrm{C} / \mathrm{O}-\mathrm{O}$ bond fission to produce acetone $\left(\mathrm{CH}_{3} \mathrm{COCH}_{3}\right)$ and acetaldehyde, as shown in Figure 8a. This reaction path is the largest source of both acetone and acetaldehyde in our simulations of $2 \mathrm{M} 2 \mathrm{~B}$ oxidation:

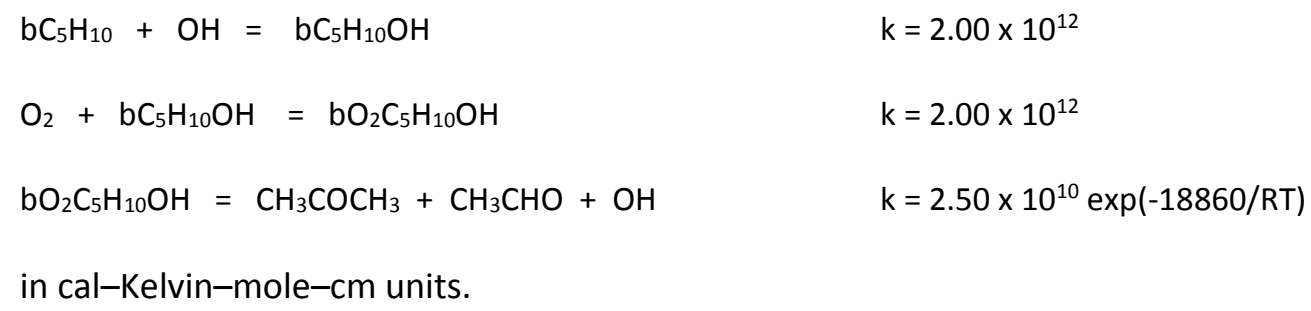

Addition of $\mathrm{HO}_{2}$ to the $\mathrm{C}=\mathrm{C}$ double bond in $\mathrm{bC}_{5} \mathrm{H}_{10}$, produces a hydroperoxy alkyl species, specifically $b_{5} \mathrm{H}_{10} \mathrm{OOH}-\mathrm{c}$ or $\mathrm{CC}_{5} \mathrm{H}_{10} \mathrm{OOH}-\mathrm{b}$ that is seen in the low temperature, alkylperoxy radical isomerization reaction pathways for 2-methylbutane (iso-pentane) $(51,52)$. Either of these species can react directly back to fuel $+\mathrm{HO}$, but some can react via cyclization to produce 2,2,3-trimethyl oxirane, as shown in Figure $8 \mathrm{~b}$, and this reaction path is the only mechanism producing this intermediate product in the present 2M2B kinetic mechanism. Addition reactions of allylic $\mathrm{C}_{5} \mathrm{H}_{9}$ radicals to the $2 \mathrm{M} 2 \mathrm{~B}$ fuel were not considered in this kinetic reaction mechanism.

The most important point here is that all of these fuel consumption reaction pathways contribute significantly to consumption of $2 \mathrm{M} 2 \mathrm{~B}$ in some or all of the temperature ranges important for practical combustion systems. Omitting any of them will severely limit the predictive capabilities of the kinetic mechanism. At sufficiently high temperatures, the radical addition reactions can be omitted with no loss of accuracy, but the present kinetic modeling described below retained all of these reaction pathways in both the high and low temperature simulations with no observable extra computer time costs or errors in the high temperature simulations. 
a) Waddington mechanism

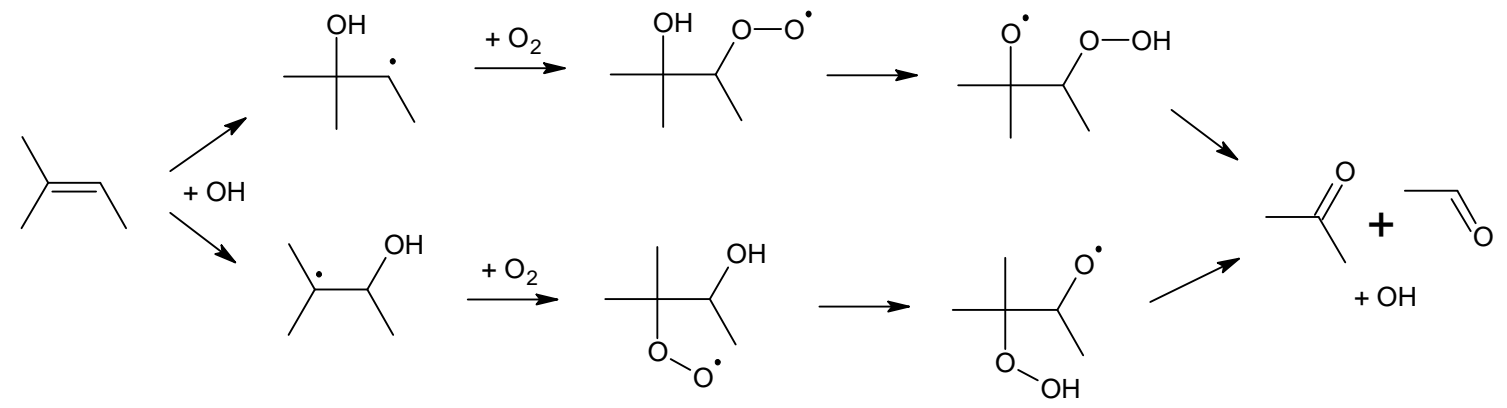

b) Addition of $\mathrm{HO}_{2}$ to olefin leading to oxirane $+\mathrm{OH}$

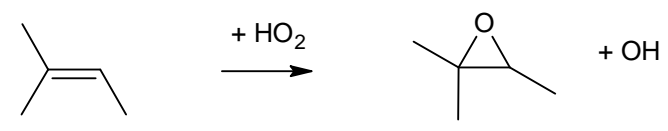

2,2,3-trimethyl-oxirane

c) Formation of carbonyl species from the recombination of $\mathrm{HO}_{2}$ and allylic radicals
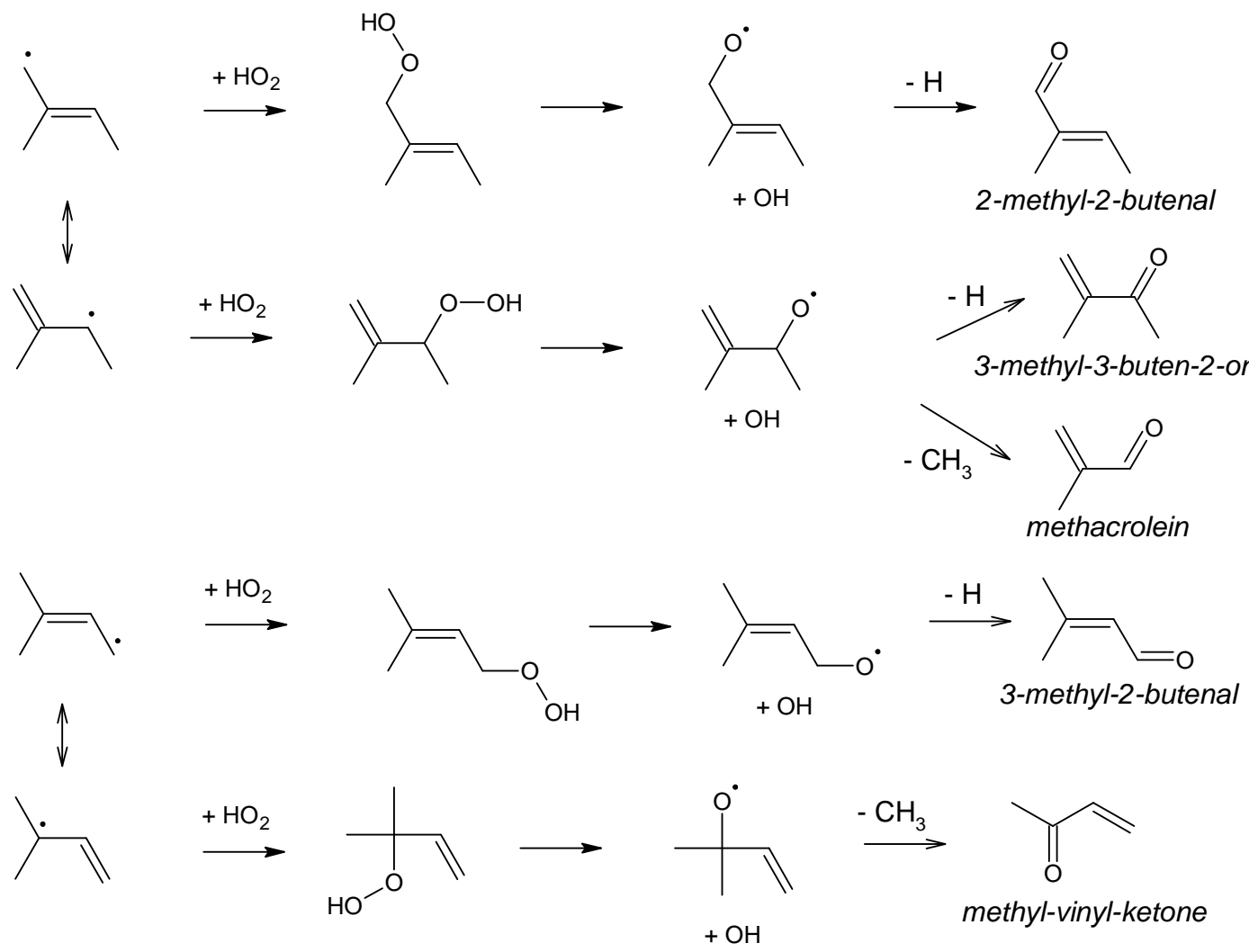

Figure 8. Mechanism of some reactions specific to $2 \mathrm{M} 2 \mathrm{~B}$ and its allylic alkenyl radical species. Reaction $\mathrm{b}$ has an additional $\mathrm{OH}$ product not shown in the figure. 


\section{Reactions of Allylic Radical Species}

The immediate products of $2 \mathrm{M} 2 \mathrm{~B}$ consumption are primarily the two allylic alkenyl radicals produced by $\mathrm{H}$ atom abstraction. The fact that no other alkenyl radicals are produced from this particular fuel is an asset for the purposes of the present study, since it avoids complications from any other competing alkenyl radical reaction pathways. The rates of reaction of the allylic pentenyl radicals have been based primarily on the recent work of Mehl et al. $(29)$ and Bugler et al. $(51,52)$ The central issue associated with resonantly stabilized allylic radicals is that their unimolecular thermal decomposition rates are much slower at temperatures below a critical value of about $900 \mathrm{~K}$ than those of alkyl and nonallylic alkenyl radicals. This trend is reflected in activation energies for thermal decomposition reactions of these allylic $\mathrm{aC}_{5} \mathrm{H}_{9}-\mathrm{c} / \mathrm{bC}_{5} \mathrm{H}_{9}$-a and $\mathrm{cC}_{5} \mathrm{H}_{9}-\mathrm{b} / \mathrm{bC}_{5} \mathrm{H}_{9}$-d radicals of more than 50 $\mathrm{kcal} / \mathrm{mol}$. These allylic radicals will resist thermal decomposition until the reaction temperature is high enough to overcome such an energy barrier. Above that critical temperature, decomposition of allylic radicals occurs quite rapidly via $\beta$-scission reactions:

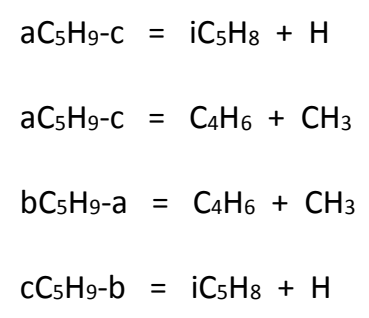

where $\mathrm{C}_{4} \mathrm{H}_{6}$ denotes 1,2-butadiene and $\mathrm{i}_{5} \mathrm{H}_{8}$ is isoprene, both of which were found to be major intermediates in both the shock tube and JSR experiments. While allylic pentenyl radicals in 2M2B decompose very slowly at lower temperatures, they react steadily with molecular oxygen over the entire temperature range of the experiments studied here, reactions that produce isoprene:

$\mathrm{aC}_{5} \mathrm{H}_{9}-\mathrm{C}+\mathrm{O}_{2}=\mathrm{iC}_{5} \mathrm{H}_{8}+\mathrm{HO}_{2}$

and similarly for the other allylic alkenyl radicals. Lee and Bozzelli (60) and Stothard and Walker (61) have shown that the rates of reactions of allyl radicals with molecular oxygen are much slower than related reactions of alkyl radicals with $\mathrm{O}_{2}$, and our model uses rates of reaction of the larger allylic pentenyl radicals with $\mathrm{O}_{2}$ that are the same as those of Stothard and Walker for allyl $+\mathrm{O}_{2}$.

Allylic radicals in 2M2B react by recombination with $\mathrm{OOH}$ to produce alkenyl hydroperoxides with a wide variety of subsequent reaction pathways: 


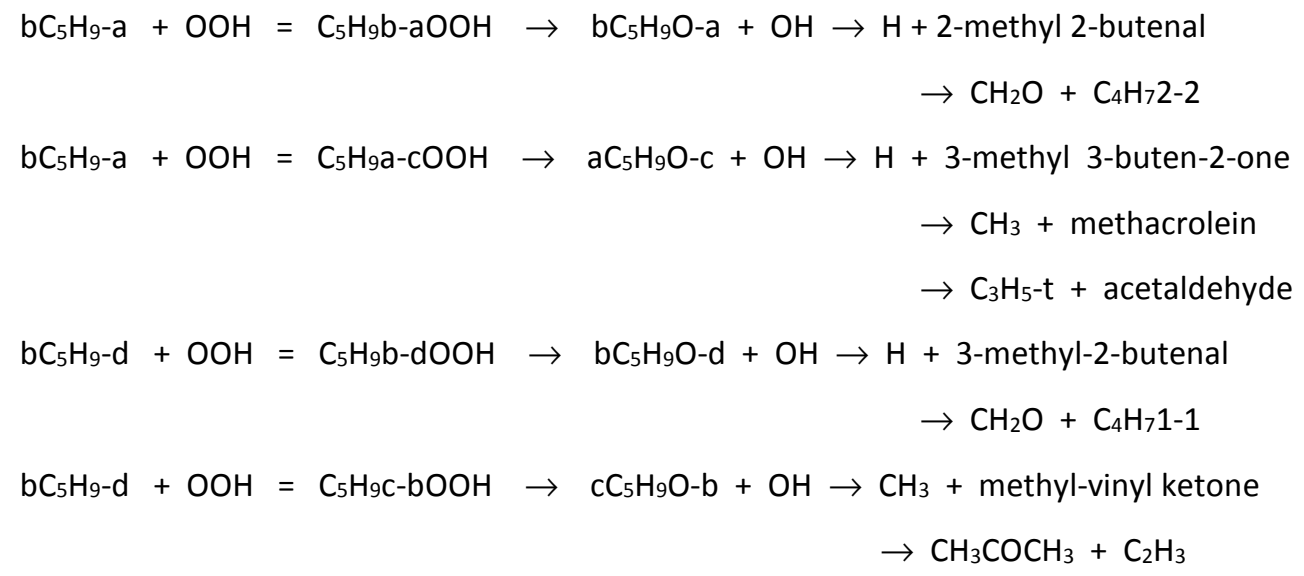

where the "dual identity" of each allylic pentenyl radicals can be seen to produce different sets of products from each radical. Five of these addition reactions and product pathways are shown schematically in Figure 8c, and all nine final product paths are summarized above. We used the allyl radical $+\mathrm{HO}_{2}$ reaction rate from Goldsmith et al. (35) for these $\mathrm{C}_{5} \mathrm{H}_{9}+\mathrm{HO}_{2}$ reaction rates in our kinetic mechanism. The stable pentenyl hydroperoxide species $\mathrm{C} 5 \mathrm{H} 9 \mathrm{~b}-\mathrm{aOOH}$, etc., decompose by breaking the $\mathrm{O}-\mathrm{O}$ bond to produce unsaturated versions of alkoxy radicals, with an activation energy of 43 $\mathrm{kcal} / \mathrm{mol}$, the same as the activation energy for decomposition of the ketohydroperoxide intermediates in the low-temperature submechanism for saturated hydrocarbon fuels. The unsaturated alkoxy radicals decompose via $\beta$-scission, making the final products shown above and in Figure 8c. The specific products of each reaction pathway are determined by the molecular structure of the $\mathrm{C}_{5} \mathrm{H}_{9}$ allylic radical originally produced from the fuel, and each oxygenated stable intermediate species is unique in the sense that it is produced in only one of these pathways, a characteristic we exploit to validate specific portions of the kinetic mechanism.

Finally, we included a full kinetic submechanism for addition reactions of $\mathrm{O}_{2}$ to the pentenyl radicals, followed by pentenylperoxy isomerizations, addition of a second $\mathrm{O}_{2}$ to the hydroperoxy alkenyl radicals, and low temperature chain branching reaction pathways. This low-temperature submechanism was based on the model of Mehl et al. (29) that demonstrated extended NTC behavior with linear isomers of hexene, but the present application to 2M2B showed no observable low temperature reactivity, consistent with previous kinetic studies for biodiesel fuels (5) in which weak allylic C-OO bonds cannot maintain allylperoxy radical levels high enough to initiate low-temperature NTC reactivity. It is also consistent with results of Bounaceur et al. (28), who concluded that isomerizations of $\mathrm{RO}_{2}$ radicals were inhibited in linear isomers of hexene when a $\mathrm{C}=\mathrm{C}$ double bond was present in the cyclic transition state. 


\section{High Temperature Shock Tube Simulations}

Experiments described above of ignition of 2M2B in oxygen, diluted with $99 \%$ argon, were simulated using the constant-volume, closed homogeneous batch reactor option in the ChemkinPro (58), and the ignition delay time was evaluated computationally with the same definition as used in the experiments, that of computing the slope of the excited state hydroxyl radical $\mathrm{OH}^{*}$ concentration versus time and extrapolating the region of most rapid increase to the time axis, as shown in Figure 1. The model computes the rate of production of $\mathrm{OH}^{*}$ via two possible sources (62),

$\mathrm{O}+\mathrm{H}+\mathrm{M}=\mathrm{OH}^{*}+\mathrm{M}$

$\mathrm{CH}+\mathrm{O}_{2}=\mathrm{CO}+\mathrm{OH}^{*}$

and an assumption that the de-excitation of the $\mathrm{OH}^{*}$ is very rapid following its production.

Comparisons between computed and experimental ignition delay times are summarized in Figures 9 and 10. Overall agreement is excellent, with all of the results within a factor of 2 over the entire temperature, equivalence ratio, and pressure ranges. There appears to be a slight trend in the computed results toward an effective activation energy slightly larger than that which could be extracted by a fit to the experimental results, but no other systematic trends can be detected from the comparison plots. Specifically, computed values of activation energies for all nine families of mixtures with different values of fuel/O2 equivalence ratio and pressure are in the range from $50-54 \mathrm{kcal} / \mathrm{mol}$. The calculated results reproduce the convergence of the $\varphi=1$ and $\varphi=2$ results at the highest pressure of $31 \mathrm{~atm}$, as well as the trends in overall activation energies for all of the groups of experiments at different pressures and equivalence ratios. As noted earlier, the computed activation energy for the $11 \mathrm{~atm}, \varphi=2.0$ case shown in Figures $9 \mathrm{~b}$ and $10 \mathrm{c}$ indicates that the experimental and computed ignition delay times are nearly identical over most of the temperature range, but the experimental points for ignition delay time at the lowest temperatures are noticeably lower than the computed results. We believe that these differences are most likely due to the difficulty of measuring long ignition delay times (considerably longer than $1.5 \mathrm{~ms}$ ). 


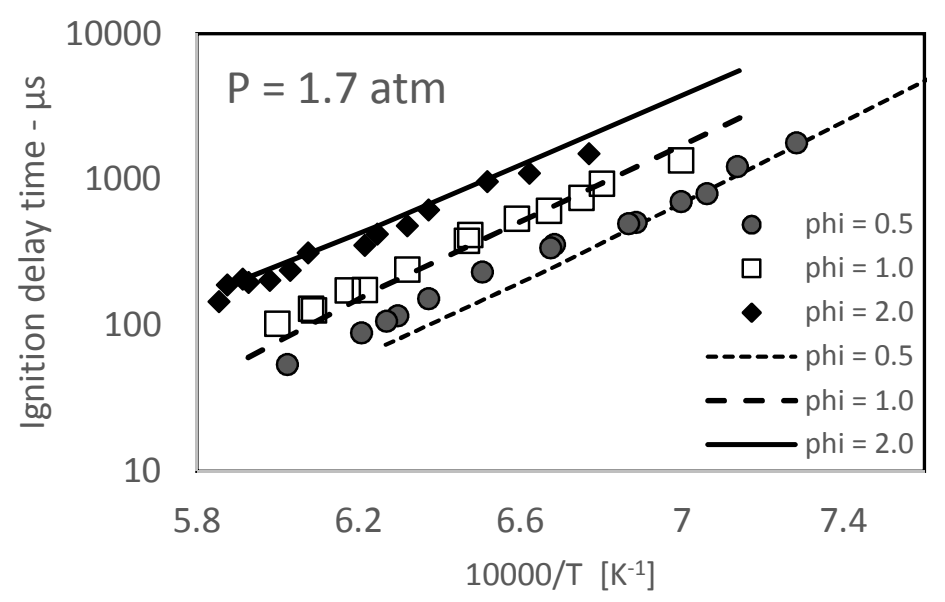

a)

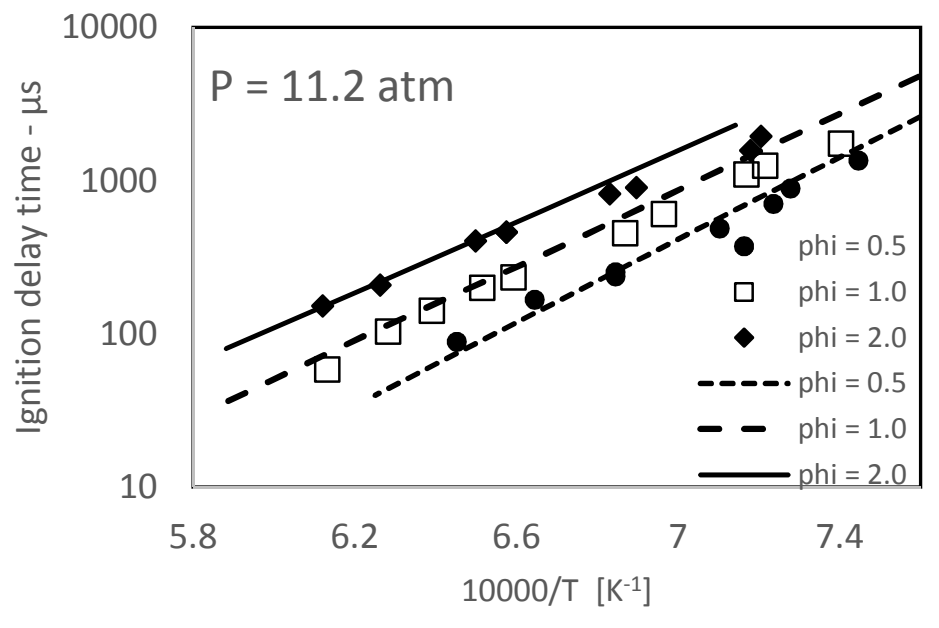

b)

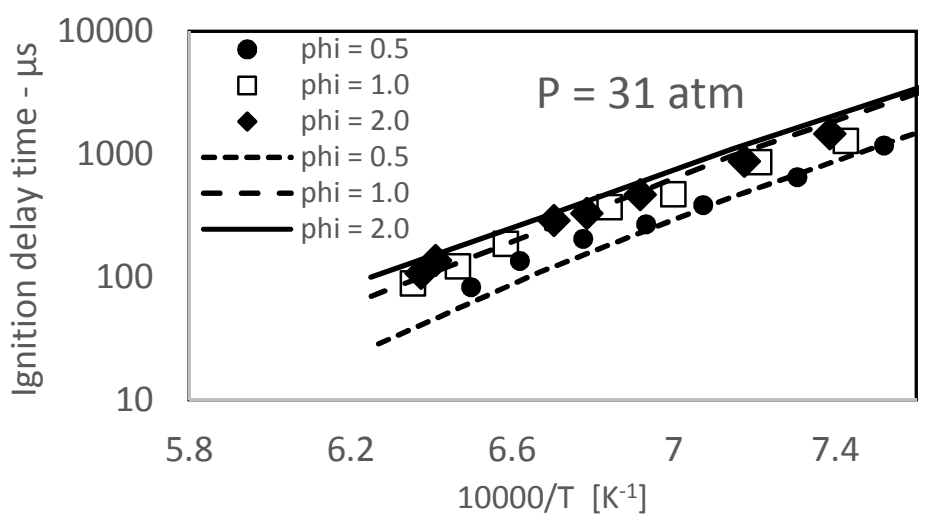

c)

Figure 9: Comparisons between experimental (symbols) and computed (lines) shock tube ignition delay times, showing the effect of equivalence ratio at (a) 1.7, (b) 11.2, and (c) $31 \mathrm{~atm}$. 

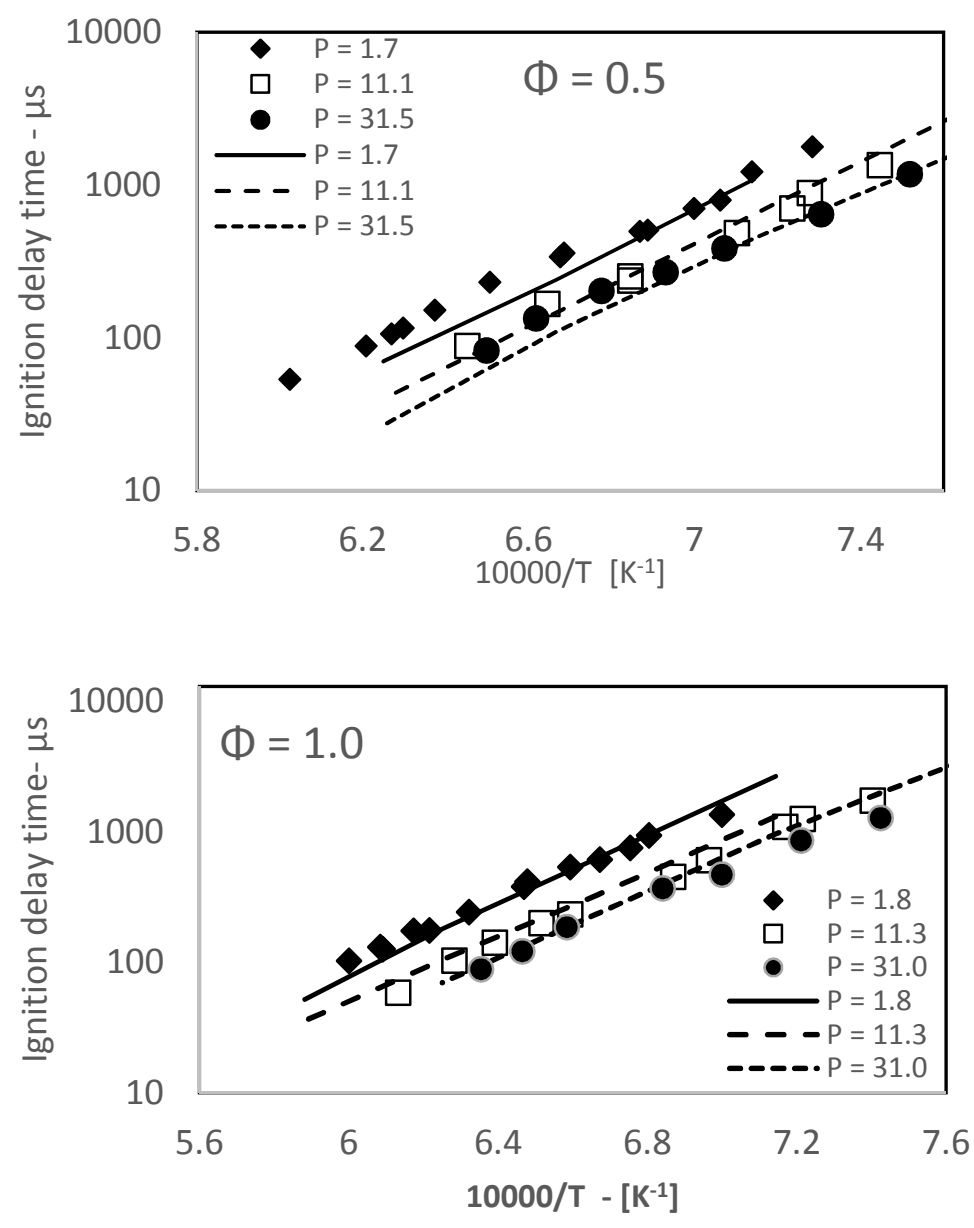

b)

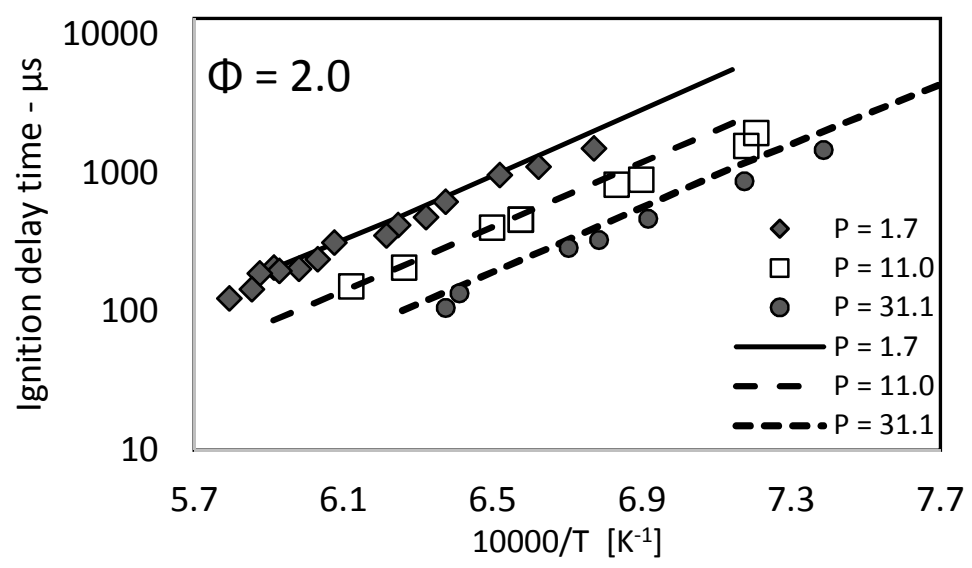

c)

Figure 10: Comparisons between experimental (symbols) and computed (lines) ignition delay times, showing effects of pressure, at equivalence ratios of (a) 0.5 , (b) 1.0, and (c) 2.0 .

We carried out a systematic sensitivity analysis for the stoichiometric mixture at 11.3 bar pressure and an initial temperature of $1500 \mathrm{~K}$, where the computed reference ignition delay time to is $350 \mu \mathrm{s}$. For each of the most sensitive reactions, the A-factor for the reaction rate was multiplied by 5.0 , and the ignition delay time $\tau$ s was again computed. The sensitivity function is then $\left(\tau_{s}-\tau_{0}\right) / \tau_{0}$, and 
these values are plotted in Figure 11. A negative value signifies that the change in the reaction rate reduced the ignition delay time. The $\mathrm{H}+\mathrm{O}_{2}=\mathrm{O}+\mathrm{OH}$ reaction has the greatest sensitivity, reducing the ignition delay time by nearly a factor of 10 for an increase in the reaction rate by a factor of 5 . Due to the dominance of the $\mathrm{H}+\mathrm{O}_{2}=\mathrm{O}+\mathrm{OH}$ reaction $(63,64)$, other reaction rates with the greatest negative sensitivity are those that produce $\mathrm{H}$ atoms, including the initiation reactions $\mathrm{bC}_{5} \mathrm{H}_{10}=\mathrm{aC}_{5} \mathrm{H}_{9}-\mathrm{c}+\mathrm{H}$ and $\mathrm{bC}_{5} \mathrm{H}_{10}=\mathrm{cC}_{5} \mathrm{H}_{9}-\mathrm{b}+\mathrm{H}$, and the small molecule reactions $\mathrm{O}+\mathrm{H}_{2}=\mathrm{OH}+\mathrm{H}, \mathrm{H}_{2}+\mathrm{OH}=\mathrm{H}+\mathrm{H}_{2} \mathrm{O}$, and $\mathrm{CO}+$ $\mathrm{OH}=\mathrm{CO}_{2}+\mathrm{H}$. The relatively higher sensitivity of the computed results to reaction rates involved in the core $C_{1}-C_{4}$ submechanism is another familiar characteristic of the present high-temperature mechanism. The two initiation reactions $\mathrm{bC}_{5} \mathrm{H}_{10}=\mathrm{C}_{4} \mathrm{H}_{7}+\mathrm{CH}_{3}$ both have positive sensitivity, an inhibition of ignition, because the two reactions compete with two other initiation reactions that produce $\mathrm{H}$ atoms. An interesting pair of reactions are those consuming formyl radicals, $\mathrm{HCO}+\mathrm{M}=\mathrm{H}+\mathrm{CO}+\mathrm{M}$ and $\mathrm{HCO}+\mathrm{O}_{2}=\mathrm{CO}+\mathrm{HO}_{2}$, the first of which accelerates the ignition, while the second retards ignition. At high temperatures, reactions producing $\mathrm{H}$ atoms usually have positive sensitivities since the $\mathrm{H}$ atoms they provide can then react with $\mathrm{O}_{2}$ and increase the overall rate of chain branching.

None of the radical addition reactions to the $2 \mathrm{M} 2 \mathrm{~B}$ fuel or to its allylic pentenyl radicals showed any significant sensitivity in these high-temperature shock tube simulations, and no low-temperature alkenyl peroxy radical isomerization reaction or allylic pentenyl hydroperoxide reaction pathways were seen in the simulations, in good agreement with the experiments. At the temperatures characteristic of these shock tube experiments, the allylic $\mathrm{C}_{5} \mathrm{H}_{9}$ radicals decompose at high rates, similar to rates of alkyl radical decompositions in other, saturated fuel high-temperature ignition. All of the sensitivity coefficients for $\mathrm{H}$ atom abstraction from 2M2B show negative values, indicating that the abstractions tend to reduce the ignition times, and all of the abstractions benefit from the weak allylic $\mathrm{C}-\mathrm{H}$ bonds in the fuel. 


\section{Sensitivities}

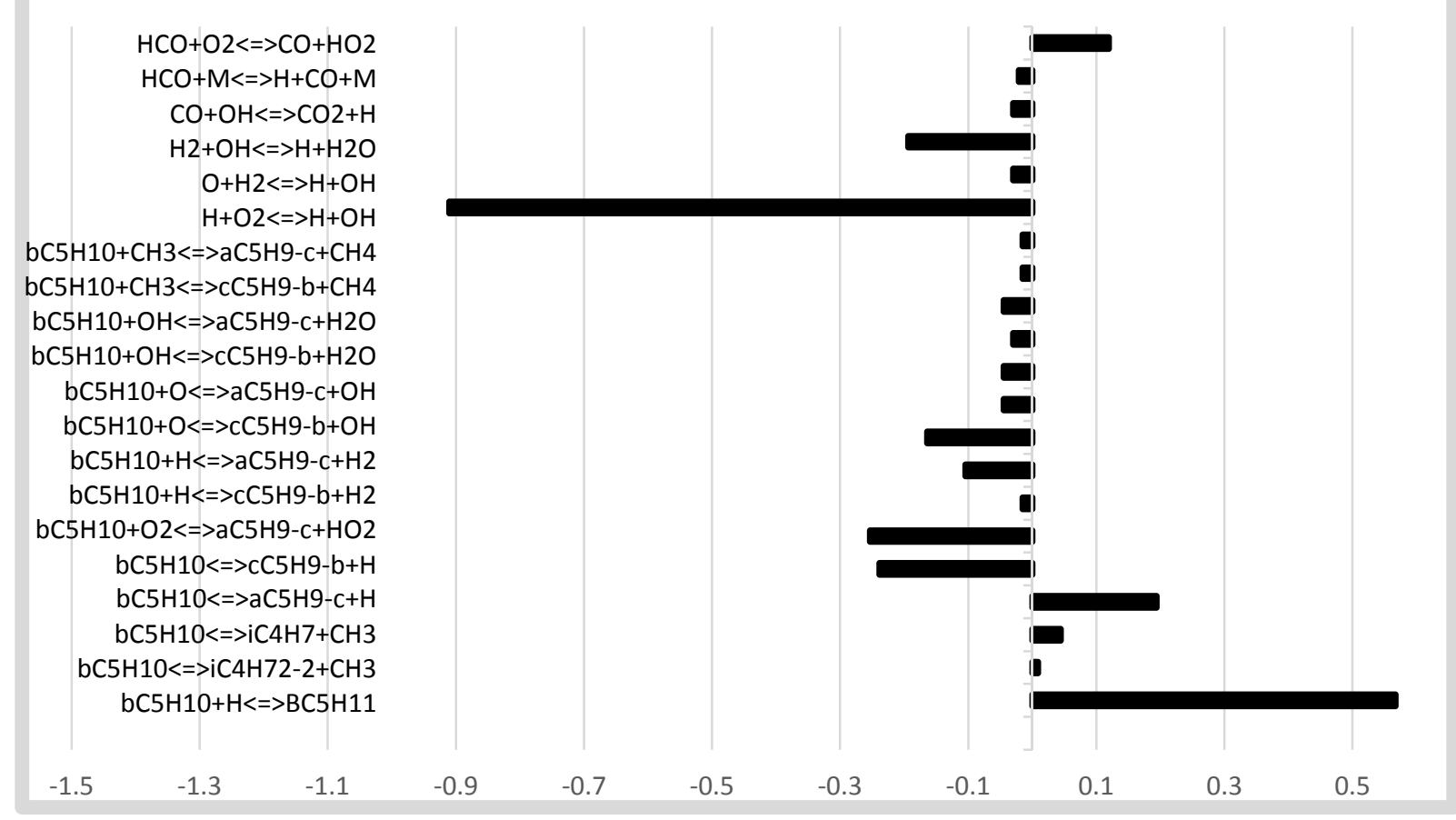

Figure 11: Sensitivity analysis of major reactions in ignition of stoichiometric $2 \mathrm{M} 2 \mathrm{~B} / \mathrm{O}_{2} / \mathrm{Ar}$ mixture,

0.01 mole fraction fuel, at $11.3 \mathrm{~atm}$ pressure and $1500 \mathrm{~K}$, with each rate increased by a factor of 5 .

Reference ignition delay time is $350 \mu$ s; negative values show faster ignition with reaction rate increase.

\section{Low and Intermediate Temperature JSR Experiment Simulations}

The jet-stirred reactor experiments were simulated using ChemkinPro with the transient PSR application (58), setting the reaction temperature fixed for each computed point, at temperature intervals of $50 \mathrm{~K}$ from $600-1100 \mathrm{~K}$. Selected computed results for a wide variety of chemical species mole fractions are plotted, together with their experimentally measured mole fractions, in Figures 46. The measured and computed species levels fall into several regimes; seven major species were present at levels above $1000 \mathrm{ppm}$, including the fuel $2 \mathrm{M} 2 \mathrm{~B}$, as well as $\mathrm{O}_{2}, \mathrm{CH}_{4}, \mathrm{C}_{2} \mathrm{H}_{4}, \mathrm{CO}, \mathrm{CO}_{2}$, and $\mathrm{iC}_{5} \mathrm{H}_{8}$ (isoprene), and 12 other species were measured at levels between 100 and 1000 ppm, including $\mathrm{C}_{2} \mathrm{H}_{2}$, $\mathrm{C}_{2} \mathrm{H}_{4}, \mathrm{C}_{3} \mathrm{H}_{6}, \mathrm{CH}_{3} \mathrm{CHO}, \mathrm{CH}_{3} \mathrm{OH}, \mathrm{iC}_{4} \mathrm{H}_{8}, 1-\mathrm{C}_{4} \mathrm{H}_{8}, \mathrm{CH}_{3} \mathrm{COCH}_{3}$ (acetone), $\mathrm{C}_{2} \mathrm{H}_{3} \mathrm{CHO}$ (acrolein), $\mathrm{CH}_{2} \mathrm{C}\left(\mathrm{CH}_{3}\right) \mathrm{CHO}$ (methacrolein), $\mathrm{C}_{2} \mathrm{H}_{3} \mathrm{COCH}_{3}$ (methyl vinyl ketone), and 2,2,3-trimethyl oxirane (223-TMO). Other species were measured or calculated at levels less than 100 ppm, including allene, propyne, 1,3-butadiene, 2-methyl 1-butene $\left(\mathrm{aC}_{5} \mathrm{H}_{10}\right), \mathrm{C}_{2} \mathrm{H}_{5} \mathrm{CHO}, 2-\mathrm{C}_{4} \mathrm{H}_{8}$, and several oxygenated hydrocarbons that are important parts of the kinetic reaction mechanism such as 3-methyl-2-butenal, 2-methyl-2butenal, and 2-methyl-3-buten-2-one. 
All seven of the species in the range above $1000 \mathrm{ppm}$ were computed at levels that agree very well with the experimentally measured values, including the $\mathrm{O}_{2}$ which was not plotted in Figure 4 . The onset of fuel consumption between 750 and $800 \mathrm{~K}$, the rapid decrease in fuel concentration between 800 and $900 \mathrm{~K}$, and the total consumption of fuel by about $1000 \mathrm{~K}$ are all reproduced very well by the model. The major intermediate species $\mathrm{CO}, \mathrm{CH}_{4}, \mathrm{C}_{2} \mathrm{H}_{4}$, and $\mathrm{iC}_{5} \mathrm{H}_{8}$ (isoprene) all reach peak values and then decrease, with good agreement compared to the experimental results for both production and consumption rates. In Figure 6, note that the experiments show that acetone $\left(\mathrm{CH}_{3} \mathrm{COCH}_{3}\right)$ is produced in larger amounts than 2,2,3-trimethyl oxirane, while the computed levels are reversed. Similarly, the experiments and computations reverse the levels of 1-butene and 2-butene.

Isoprene, as well as other intermediates $\mathrm{CH}_{3} \mathrm{CHO}, \mathrm{CH}_{3} \mathrm{OH}, \mathrm{C}_{3} \mathrm{H}_{6}, \mathrm{aC}_{5} \mathrm{H}_{10}, \mathrm{iC}_{4} \mathrm{H}_{8}$, acetone, 3-methyl-2-butenal, methacrolein, 3-methyl-2-butenal, 2-methyl-3-buten-2-one, $\mathrm{C}_{2} \mathrm{H}_{3} \mathrm{COCH}_{3}$, and 2,2,3-trimethyl oxirane reach their peak values at temperatures of $850-900 \mathrm{~K}$, while other intermediates $\mathrm{CO}, \mathrm{CH}_{4}, \mathrm{C}_{2} \mathrm{H}_{4}, \mathrm{C}_{2} \mathrm{H}_{6}$, and butadiene reach their peak concentrations at higher temperatures of $950-1050 \mathrm{~K}$. This sequence is very consistent with a conceptual understanding that the low-temperature oxidation of 2M2B takes place in stages, the first being the conversion of the fuel to smaller hydrocarbon species by reactions specific to the fuel structure, while the second stage is the more familiar oxidation of $C_{2}, C_{3}$, and $C_{4}$ species to final products. However, the first stage of the oxidation has a rather novel structure that is imposed by somewhat unusual features of the kinetics of allylic radical oxidation.

Mole fractions of $2 \mathrm{M} 2 \mathrm{~B}, \mathrm{cC}_{5} \mathrm{H}_{9}-\mathrm{b}, \mathrm{C}_{5} \mathrm{H}_{9} \mathrm{a}-\mathrm{cOOH}$, and $\mathrm{H}_{2} \mathrm{O}_{2}$ are plotted in Figure 12 , to illustrate these stages in low-temperature oxidation of $2 \mathrm{M} 2 \mathrm{~B}$, scaling each appropriately to illustrate the sequence of the stages.

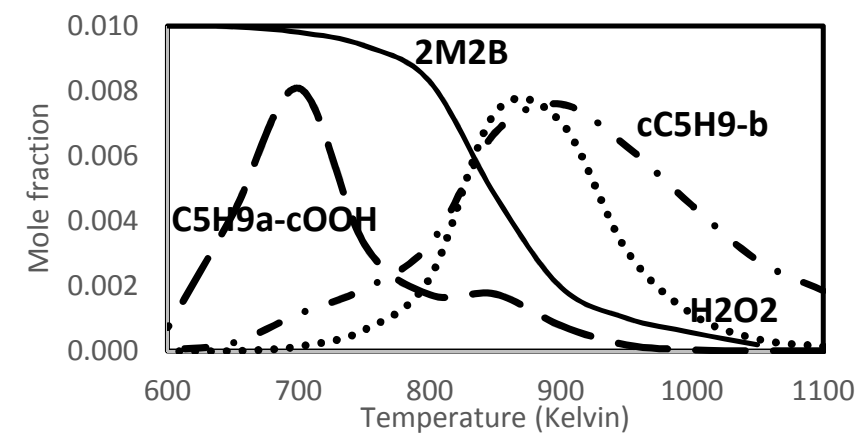

Figure 12: Computed mole fractions of fuel $2 \mathrm{M} 2 \mathrm{~B}$ and selected representative metastable intermediates in JSR simulations at 1.06 bar pressure and residence time of $1.5 \mathrm{~s}$. The mole fractions of $\mathrm{C}_{5} \mathrm{H}_{9} \mathrm{a}-\mathrm{COOH}$ have been multiplied by 107 , the mole fractions of $\mathrm{cC}_{5} \mathrm{H}_{9}-\mathrm{b}$ have been multiplied by 3000 , and the mole fractions of $\mathrm{H}_{2} \mathrm{O}_{2}$ have been multiplied by 20 , to permit comparisons in behavior. 
At the lowest temperatures studied, from $600 \mathrm{~K}$ to about $700 \mathrm{~K}$, the fuel is consumed quite slowly by initiation reactions between fuel and molecular oxygen and then by other $\mathrm{H}$ atom abstraction reactions which convert fuel to allylic pentenyl radicals. The temperature is too low for decomposition of the $\mathrm{aC}_{5} \mathrm{H}_{9}-\mathrm{C}$ and $\mathrm{CC}_{5} \mathrm{H}_{9}-\mathrm{b}$ radicals because of the $51.5 \mathrm{kcal} / \mathrm{mol}$ activation energies of those decompositions, but low activation energy combination reactions $\mathrm{A} 1-\mathrm{A} 9$ of these radicals with $\mathrm{HO}_{2}$ produce the four isomers of metastable alkenyl hydroperoxides (e.g., $\mathrm{C}_{5} \mathrm{H}_{9} \mathrm{a}-\mathrm{cOOH}$ in Figure 12) as discussed above. Until the temperature reaches about $700 \mathrm{~K}$, the allylic pentenyl radicals and allylic pentenyl hydroperoxides cannot decompose, so the concentrations of these radicals continue to increase. Also at these lowest temperatures, addition reactions of $\mathrm{H}, \mathrm{OH}$, and $\mathrm{HO}_{2}$ to the fuel consume small amounts of the fuel.

While radical recombination reactions of allylic pentenyl radicals with $\mathrm{HO}_{2}$ take place rapidly, without activation energy barriers, the relatively stable allyl pentenyl hydroperoxide species do not decompose immediately at lower temperatures. The activation energies of these allyl pentenyl hydroperoxide decomposition reactions are assumed in the present model to be $42.5 \mathrm{kcal} / \mathrm{mol}$, similar to comparable reactions in oxidation of linear alkenes (26) and for alkyl hydroperoxide and ketohydroperoxide species decomposition reactions that break the same type of $\mathrm{O}-\mathrm{O}$ bond $(26,37,51,52)$. At temperatures below that needed for the allylic pentenyl hydroperoxide species to decompose rapidly, these combination reactions provide "temporary" chain termination and degenerate chain branching. Once these species reach a temperature where they can rapidly decompose to two reactive radical species, specifically $\mathrm{OH}$ radicals and unsaturated alkoxy radicals, they provide chain branching and develop into slightly more rapid combustion, but at lower temperatures they are obstacles to oxidation of the $\mathrm{bC}_{5} \mathrm{H}_{10}$ fuel.

Battin-Leclerc et al. (26) discussed the differences between this example of degenerate chain branching and that of hydrogen peroxide, noting that the decompositions of alkenyl hydroperoxides, which have activation energies of around $43 \mathrm{kcal} / \mathrm{mol}$, decompose at lower temperature than $\mathrm{H}_{2} \mathrm{O}_{2}$, with its decomposition reaction activation energy of about $51 \mathrm{kcal} / \mathrm{mol}$. The role of thermal decomposition of $\mathrm{H}_{2} \mathrm{O}_{2}$ and resulting degenerate chain branching on ignition has been discussed (65) for many hydrocarbons, demonstrating the importance of its decomposition in practical combustion systems. Phenomena such as engine knock, desirable ignition in diesel and other compression-ignition engines, and important combustion metrics such as Octane Numbers and Cetane Numbers are all strongly influenced by the fact that $\mathrm{H}_{2} \mathrm{O}_{2}$ does not decompose rapidly until the gas temperature reaches about 950-1100 K, when $\mathrm{H}_{2} \mathrm{O}_{2}$ starts to be consumed rapidly via thermal decomposition. The reason for this very temperature-dependent decomposition is reflected in its activation energy of about $51.5 \mathrm{kcal} / \mathrm{mol}$. Hydrocarbon thermal autoignition is therefore slow for all alkane fuels and must wait until the temperature exceeds this critical value of about 950-1100 K. A careful look at Figure 12 
will show $\mathrm{H}_{2} \mathrm{O}_{2}$ decomposing at about $850 \mathrm{~K}$, but we must recall that Figure 12 describes oxidation at atmospheric pressure. Ignition in a diesel or spark-ignition engine takes place at pressures much higher than atmospheric, and at such higher pressures, the decomposition temperature increases, due primarily to Le Châtelier's principle.

The key to understanding oxidation and autoignition in both alkane and olefin fuels is that both really have more than one temperature-dependent obstacle to their complete combustion. In the present discussion for the olefin fuel 2M2B, there are three different critical decomposition reactions, first of the allylic pentenyl hydroperoxide species, followed by the allylic pentenyl radicals, and finally of $\mathrm{H}_{2} \mathrm{O}_{2}$. The corresponding thermal decomposition reactions have activation energies of about 42.5, 50 , and $51.5 \mathrm{kcal} / \mathrm{mol}$, and from Figure 12, reacting in the JSR at 1.06 bar pressure and a residence time of $1.5 \mathrm{~s}$, under very dilute but stoichiometric conditions, these decompositions occur at about 700 , 850 , and $850 \mathrm{~K}$, respectively, so in this example the three critical decompositions appear to occur at only two distinct reaction temperatures. For alkane fuels, there are two main decompositions that lead to autoignition $(11,37)$, consisting of the decomposition of the ketohydroperoxide intermediate species and then the decomposition of $\mathrm{H}_{2} \mathrm{O}_{2}$. Accumulation of ketohydroperoxides produce some degenerate chain branching that is released when ketohydroperoxides decompose, and the allylic pentenyl hydroperoxides in $2 \mathrm{M} 2 \mathrm{~B}$ oxidation have the same function. For ketohydroperoxide decomposition, the same type of $\mathrm{O}-\mathrm{O}$ bond must be broken as that in the allylic pentenyl hydroperoxide species produced in low-temperature olefin oxidation, so it is not surprising that both have approximately the same bond energies, and the decomposition reactions have approximately the same activation energies (42.5 vs $43 \mathrm{kcal} / \mathrm{mol}$ ), so those decompositions occur at about the same temperatures. At different dilutions or pressures, the decomposition temperatures could be slightly different, but the differences should be expected to be the same for the ketohydroperoxide and allylic hydroperoxide species, since the same $\mathrm{O}-\mathrm{O}$ bond is broken in each type of fuel. However, low reactivity of the allylic pentenyl species, including a low net rate of addition of molecular oxygen to provide conventional low-temperature reactivity, means that the amounts of allylic pentenyl hydroperoxides are smaller than levels of ketohydroperoxides in alkane fuel reactions. Thus, the amount of degenerate chain branching in $2 \mathrm{M} 2 \mathrm{~B}$ is much less than in conventional hydrocarbon oxidation, as is the amount of heat release subsequent to these decompositions, resulting in virtually no NTC behavior for $2 \mathrm{M} 2 \mathrm{~B}$ oxidation.

Decomposition of $\mathrm{H}_{2} \mathrm{O}_{2}$ is clearly common to both alkane and olefin fuels. The only feature that could vary from one olefin fuel to another is the bond that must be broken to decompose the allylic fuel radicals that are produced by $\mathrm{H}$ atom abstraction from the fuel. As can be seen in Figure 12, the stability of these allylic radicals from 2M2B leads to a decomposition reaction with an activation energy of about $50 \mathrm{kcal} / \mathrm{mol}$. Detailed analysis of the thermochemistry of the entire class of allylic radicals 
from olefin fuels is needed to determine if $50 \mathrm{kcal} / \mathrm{mol}$ is a fairly constant activation energy for their decomposition reactions, but for $2 \mathrm{M} 2 \mathrm{~B}$, these activation energies are very similar to the activation energy for $\mathrm{H}_{2} \mathrm{O}_{2}$ decomposition, so the temperatures at which these two decompositions occur for 2M2B are very similar, as seen for the $\mathrm{H}_{2} \mathrm{O}_{2}$ and $\mathrm{cC}_{5} \mathrm{H}_{9}$-b decompositions in Figure 12.

These "critical decomposition temperatures" for 2M2B depend somewhat on pressure, increasing as the pressure increases. The present experiments and model computations were carried out at close to atmospheric pressure, and the critical temperatures will be higher for engine combustion conditions. At atmospheric pressure in the present experiments and computations, the activation energies for the allylic pentenyl hydroperoxide species decomposition reactions delay oxidation at temperatures below about $700 \mathrm{~K}$, and subsequent decomposition reactions of the allylic pentenyl radicals at about $875 \mathrm{~K}$ begin to support more rapid reaction at higher temperatures where the stability of the allylic pentenyl radicals is no longer an inhibiting factor. Decomposition of $\mathrm{H}_{2} \mathrm{O}_{2}$ follows quite rapidly that of the allylic pentenyl radicals, since their decomposition reaction activation energies are not very different. Above 950-1100 K, none of these reaction pathways are capable of delaying rapid reaction of $2 \mathrm{M} 2 \mathrm{~B}$, so its reaction becomes a purely high-temperature process, as seen above for high-temperature ignition behavior.

This concept of fuel consumption occurring in a sequence of stages, depending on the temperature, can be seen in the plots of species mole fractions and the temperatures at which each species begins to grow, as seen in Figure 12. It is clear that the first species produced such as the allylic pentenyl radicals and pentenyl hydroperoxides start to appear around $600 \mathrm{~K}$, as well as acetaldehyde $\left(\mathrm{CH}_{3} \mathrm{CHO}\right)$ (Figure 5) and acetone $\left(\mathrm{CH}_{3} \mathrm{COCH}_{3}\right)$ (Figure 6) which are produced by the Waddington mechanism of the fuel at low temperature, but no other intermediates appear until about $700 \mathrm{~K}$, where the species produced from decomposition of the allylic pentenyl hydroperoxides, including isoprene $\left(\mathrm{iC}_{5} \mathrm{H}_{8}\right)$, methacrolein, methyl vinyl ketone, 2,2,3-trimethyl oxirane, 2-methyl-2-butenal, 3-methyl-2butenal, and 2-methyl-3-buten-2-one begin to appear. Methanol production is part of this first-generation of intermediates, since its main production comes from $\mathrm{H}$ atom abstraction from the fuel by methoxy $\left(\mathrm{CH}_{3} \mathrm{O}\right)$ radicals. Then the second generation of intermediate species is produced, primarily from continued oxidation of the first-generation intermediates, starting around $800 \mathrm{~K}$. This second generation family of intermediates includes $\mathrm{CH}_{4}, \mathrm{C}_{2} \mathrm{H}_{4}, \mathrm{CO}, \mathrm{C}_{2} \mathrm{H}_{2}, \mathrm{C}_{2} \mathrm{H}_{6}, \mathrm{C}_{3} \mathrm{H}_{6}$, and $\mathrm{C}_{4} \mathrm{H}_{8}$, and significant production of final products, represented by $\mathrm{CO}_{2}$, does not begin until most other intermediates have been consumed at about $1050 \mathrm{~K}$.

This reaction sequence is an important source of both acetone and acetaldehyde in this system, both of which are slightly underpredicted by the present reaction mechanism. This sequence is particularly important at the lowest reaction temperatures because the activation energies for each step are low. Since this reaction path favors low temperatures, it also plays a significant role in 
determining the temperature where the overall reaction begins. Increasing the rate of the Waddington mechanism reaction of $\mathrm{bC}_{5} \mathrm{H}_{10}$ with $\mathrm{OH}$ by a factor of 2.0, hoping to increase computed levels of acetone and acetaldehyde and improve agreement with experimental levels, produced an onset of rapid fuel consumption before $650 \mathrm{~K}$, inconsistent with the experimental results shown in Figure 4, where the onset of rapid fuel consumption begins about $800 \mathrm{~K}$.

Once the temperature reaches about $800 \mathrm{~K}$, the overall nature of the $2 \mathrm{M} 2 \mathrm{~B}$ oxidation changes again. At this temperature, the allylic pentenyl hydroperoxide species decompose quite rapidly, due to the $42.5 \mathrm{kcal} / \mathrm{mol}$ activation energy for their decomposition reactions, leading to more rapid fuel consumption. Most of the fuel consumption occurs between 800 and $950 \mathrm{~K}$, producing increasing mole fractions of the allylic pentenyl radicals as well as other metastable species, including $\mathrm{H}_{2} \mathrm{O}_{2}$ as shown in Figure 12. Note that the allylic pentenyl radical, with decomposition reaction activation energies of about $51.5 \mathrm{kcal} / \mathrm{mol}$, still does not decompose rapidly until the temperature reaches about $875 \mathrm{~K}$, although the overall rate of reaction is accelerating significantly. Recall that this value is almost the same activation energy as that for $\mathrm{H}_{2} \mathrm{O}_{2}$ decomposition, as discussed above, and plotting the $\mathrm{H}_{2} \mathrm{O}_{2}$ mole fractions in Figure 12 confirms that the decomposition of the allylic pentenyl radicals reaches a maximum at about the same temperature as that of $\mathrm{H}_{2} \mathrm{O}_{2}$. The rapid consumption of fuel between 800 and $950 \mathrm{~K}$ releases enough heat to increase the temperature to decompose the remaining allylic pentenyl radicals and the $\mathrm{H}_{2} \mathrm{O}_{2}$.

The present experiments demonstrate reaction on both sides of these transition temperatures. The kinetic mechanism reproduces the observed reactivity, with a smooth transition between those regimes. We carried out some preliminary kinetic modeling studies of these low and intermediate temperature oxidation condition for $2 \mathrm{M} 2 \mathrm{~B}$ using a semidetailed kinetic reaction developed using the EXGAS mechanism generation software (57) to which new features were recently added (28) to provide kinetics specifically related to olefins fuels. The overall performance of this preliminary mechanism was very good, and the relative simplicity of the model permitted us to identify the portions of the detailed mechanism that were most important and therefore required the most attention. The fuel mole fractions computed with this preliminary mechanism are plotted as the third fuel profile in Figure 4, showing the correct onset of reaction at $750-800 \mathrm{~K}$ and a good representation of the temperature range over which the fuel consumption takes place.

\section{Discussion}

The combined results of the high- and low/intermediate-temperature kinetic mechanism described above illustrate that this mechanism is an acceptable model for oxidation of 2-methyl-2butene for the specific conditions used for validation of the mechanism. A major point of this paper is that there are very few published experimental studies available for validation of kinetic mechanisms 
for any unsaturated branched hydrocarbon fuels, particularly those in which intermediate chemical species concentrations have been reported. The stirred reactor and shock tube experimental results presented in this work are the first, to our knowledge, for any branched pentenes, and the JSR experiments are the first for any branched hydrocarbons larger than iso-butene in which intermediate species concentrations have been measured. We expect that the present mechanism will require updating when future experimental data become available; experiments in a rapid compression machine or laminar premixed flame in which species concentrations can be measured would be particularly valuable. For example, the present $2 \mathrm{M} 2 \mathrm{~B}$ JSR experiments show that the ratio of 1,3-butadiene to 1,2-butadiene is about 5/1, but the kinetic mechanism lumps together both isomers, due to a lack of more specific reaction pathways for the two species, and more experiments with species-specific measurements are needed to improve this part of the kinetic mechanism. More generally, the lack of kinetic experiments for mechanism validation is an obstacle for inclusion of similar mechanisms for other branched isomers of iso-pentene with the current model.

The present model shows that a single kinetic mechanism can be applicable to simulations of allylic radical reactions, covering a wide range of temperatures. Details in the consumption of the allylic alkenyl radicals are quite complex and change significantly between the lower-temperature conditions encountered in the JSR experiments and the higher temperatures addressed in the shock tube conditions. The present fuel was selected for study because it is dominated by allylic $\mathrm{C}-\mathrm{H}$ bonds, and its oxidation produces a high fraction of resonantly stabilized pentenyl radicals, free of complications from the participation of conventional primary, secondary, and tertiary $\mathrm{C}-\mathrm{H}$ bonds present in most hydrocarbon fuels. The experiments and kinetic model experience no observable low temperature, negative temperature coefficient (NTC) behavior, even though moderate levels of the $\mathrm{aC} 5 \mathrm{H} 10$ and $\mathrm{cC} 5 \mathrm{H} 10$ isomers and their pentenyl radicals are produced during the reaction of bC5H10 fuel, but their concentrations are not high enough to activate NTC behavior. As described by Leppard,(8) this lack of NTC behavior is related to the high octane sensitivity of 2M2B, and the lack of low-temperature reactivity is, in turn, due to the low reactivity of small allylic radical species at low temperatures, which includes their inability to produce alkenylperoxy radicals that could lead to NTC behavior.

We have emphasized the dominance of resonantly stabilized pentenyl radicals in our discussions, and we believe that there are important practical implications of the complete lack of NTC behavior in the present study. Three factors have been suggested as molecular-level causes of octane sensitivity and poor low-temperature reactivity. These include (a) low reactivity of allylic radical species at low temperatures as noted in the present work, but other explanations include (b) the effects of weak allylic and bis-allylic $\mathrm{C}-\mathrm{O}$ bonds that inhibit the stability of peroxy radical isomerization reactions that lead to cool flames and NTC behavior (5), as well as (c) the reduction in the length of uninterrupted chains of secondary $-\mathrm{CH}_{2}-$ groups when a $\mathrm{C}=\mathrm{C}$ double bond is introduced into such a chain $(27-29,36)$. 
Leppard (8) discusses differences in the standardized tests for RON and MON, noting that MON emphasizes a higher-temperature ignition regime than the RON test, so a fourth possible source of octane sensitivity could be the higher reactivity of the allylic $\mathrm{C}-\mathrm{H}$ bonds at high temperatures. We note from the sensitivity analysis in Figure 11 that increasing the rate of any of the $\mathrm{H}$ atom abstraction rates at the allylic sites in $2 \mathrm{M} 2 \mathrm{~B}$ accelerated ignition at high temperatures, increased high-temperature reactivity that is consistent with a reduced MON value.

These effects are consistent with recent comparisons of low-temperature reactivity between linear isomers of pentene and hexene discussed above, in which ignition of the linear isomers of pentene and hexene have been compared with the saturated fuels $n$-pentane and $n$-hexane. For both linear fuel families, low-temperature ignition was found to be fastest for the $n$-alkane, followed by the 1-alkene, then the 2-alkene and, in the case of $C_{6}$, 3-hexene ignited slowest. The amounts of NTC behavior decreased as the $\mathrm{C}=\mathrm{C}$ double bond moved away from the end of the carbon chain and nearly disappears for 3-hexene. In these fuels, the 1-olefin has only 2 secondary allylic $\mathrm{C}-\mathrm{H}$ bonds, the 2-olefin has 2 secondary allylic $\mathrm{C}-\mathrm{H}$ bonds, and 3 primary allylic $\mathrm{C}-\mathrm{H}$ bonds, and 3 -hexene has a full complement of four secondary allylic $\mathrm{C}-\mathrm{H}$ bonds, corresponding closely to the steadily decreasing amount of lowtemperature reactivity. Moving the $\mathrm{C}=\mathrm{C}$ double bonds to the center of the chain also reduces the length of the uninterrupted chain of $-\mathrm{CH}_{2}-$ groups, so more than one factor appears responsible for the observed effects.

The study of Battin-Leclerc et al. (26) shows that this ordering of reactivity of isomers of linear olefins applies only to the lowest range of reaction temperatures that varies from $600-700 \mathrm{~K}$, depending primarily on the reaction pressure. As the temperature passes this transition temperature, the overall nature of the oxidation changes, including the ordering of the reactivity of the pentene and hexene isomers as first observed by Battin-Leclerc et al. Above this transition temperature, the ordering of the reactivity of the linear olefins reverses, and the significant acceleration of the overall reaction, both in the current study of $2 \mathrm{M} 2 \mathrm{~B}$ and in the previous study of the isomeric hexenes, signifies a profound change in the reaction pathways. The implication is that consumption of fuel, production of allylic and alkylic alkenyl radicals, and overall rate of heat release are discouraged by production of allylic radicals below this critical temperature, but above it, allylic radicals accelerate the overall rate of combustion.

The only constant factor that connects the low temperature and higher temperature reaction regimes for $2 \mathrm{M} 2 \mathrm{~B}$ and other olefin fuels is that allylic $\mathrm{C}-\mathrm{H}$ bonds are weaker than the primary, secondary, or tertiary $\mathrm{C}-\mathrm{H}$ bonds in saturated hydrocarbon fuels, so $\mathrm{H}$ atom abstraction is fastest for $\mathrm{H}$ atoms at allylic sites in the fuel at all temperatures. Olefin fuels, especially $2 \mathrm{M} 2 \mathrm{~B}$, pay a reactivity price at low temperatures where the resulting allylic radicals are too stable to decompose rapidly, so many olefin fuels have little or no low-temperature reactivity. At temperatures high enough for the 
allylic radicals to decompose rapidly, there is no ignition penalty for those radicals, and the higher $\mathrm{H}$ atom abstraction rate for olefins produces ignition that is faster than ignition of fuels without allylic $\mathrm{C}-\mathrm{H}$ bonds, and therefore the olefin fuel, $2 \mathrm{M} 2 \mathrm{~B}$ in the present work, actually ignites faster than otherwise comparable alkane fuels, resulting in MON values that are lower than the MON values for comparable alkane fuels and leading to the observed high octane sensitivity of olefins. Further experimental and kinetic modeling study is needed to explore these complex kinetic phenomena.

\section{Conclusion}

This paper presents results of two new experimental studies on the oxidation of 2-methyl-2butene (2M2B), consisting of high-temperature (1330-1730K) shock-tube ignition of lean, rich, and stoichiometric mixtures of $2 \mathrm{M} 2 \mathrm{~B}$ in oxygen, diluted with $99 \% \mathrm{Ar}$, at pressures of approximately 1.7, 11.2 , and $31 \mathrm{~atm}$, and jet-stirred reactor oxidation of stoichiometric mixtures of 2M2B, diluted in helium with 0.01 mole fraction of fuel, at 800 Torr pressure and temperatures from $600-1100 \mathrm{~K}$. A detailed chemical kinetic reaction mechanism was developed and used to analyze the important chemical reaction pathways that determine the oxidation of the fuel in these experiments. These are, to the best knowledge of the authors, the first such experiments and detailed chemical kinetic reaction mechanism, for any unsaturated, branched hydrocarbon fuel larger than iso-butene in which chemical intermediate species concentrations have been reported and compared with a kinetic model. The fuel, $2 \mathrm{M} 2 \mathrm{~B}$, was selected for this study due to the dominant role played by allylic $\mathrm{C}-\mathrm{H}$ bonds and production of primarily allylic fuel radical species during its oxidation. The experiments and kinetic model show that allylic pentenyl radicals inhibit low-temperature reactivity of this fuel but slightly enhance its hightemperature reactivity, consistent with the known high octane sensitivity of $2 \mathrm{M} 2 \mathrm{~B}$ and other olefinic fuels, but a more general description of all of the factors influencing fuel octane sensitivity will require further study.

\section{Supporting Information}

The experimental data for JSR species concentrations and shock-tube ignition delay times. Also, the chemical kinetic reaction mechanism and thermodynamic parameters for species in Chemkin format.

\section{Acknowledgment}

The authors thank Dr. Ellen Meeks of Reaction Design, who first suggested this study of 2methyl 2-butene. The work at LLNL was supported by the U.S. Department of Energy, Office of Basic 
Energy Sciences (program manager, Wade Sisk), Vehicle Technologies Office (program manager Gurpreet Singh and Leo Breton) and was performed under the auspices of the U.S. Department of Energy by Lawrence Livermore National Laboratory under Contract DE-AC52-07NA27344. The efforts at Texas A\&M University were supported, in part, by the TEES Turbomachnery Laboratory. The work at the Universite de Lorraine was supported by the European Commission through the "Clean ICE" Advanced Research Grant of the European Research Council. NUI Galway would like to acknowledge the support of the Irish Research Council in funding their portion of this work.

\section{References}

1. Westbrook, C. K.; Mizobuchi, Y.; Poinsot, T.; Smith, P. A.; Warnatz, J., Computational Combustion, Proc. Combust. Inst. 2005, 30, 125- 157.

2. Westbrook, C. K.; Pitz, W. J.; Herbinet, O.; Curran, H. J.; Silke, E. J., A Comprehensive Detailed Chemical Kinetic Reaction Mechanism for Combustion of $n$-Alkane Hydrocarbons From $n$-Octane to $n$-Hexadecane, Combust. Flame 2009, 156, 181- 199.

3. Sarathy, S. M.; Westbrook, C. K.; Mehl, M.; Pitz, W. J.; Togbe, C.; Dagaut, P.; Wang, H.; Oehlschlaeger, M. A.; Niemann, U.; Seshadri, K., Comprehensive Chemical Kinetic Modeling of the Oxidation of 2-methyl Alkanes from $\mathrm{C}_{7}$ to $\mathrm{C}_{20}$, Combust. Flame 2011, 158, 2338- 2357.

4. Oehlschlaeger, M. A.; Steinberg, J.; C. K. Westbrook, C. K.; Pitz, W. J., The Autoignition of iso-Cetane at High to Moderate Temperatures and Elevated Pressures: Shock Tube Experiments and Kinetic Modeling, Combust. Flame 2009, 156, 2165- 2172.

5. Westbrook, C. K.; Naik, C. V.; Herbinet, O.; Pitz, W. J.; Mehl, M.; Sarathy, S. M.; Curran, H. J., Detailed Chemical Kinetic Reaction Mechanisms for Soy and Rapeseed Biodiesel Fuels, Combust. Flame 2011, 158, 742- 755.

6. Som, S.; Liu, W.; Zhou, D. D. Y.; Magnotti, G. M.; Sivaramakrishnan, R.; Longman, D. E.; Skodje, R. T.; Davis, M. J., Quantum Tunneling Affects Engine Performance, J. Phys. Chem. Lett. 2013, 4, 2021- 2025.

7. Lovell, W. G., Knocking Characteristics of Hydrocarbons, Ind. Eng. Chem. 1948, 40, 2388- 2438.

8. Leppard, W. R., The Chemical Origin of Fuel Octane Sensitivity. SAE Paper 902137, SAE: Warrendale, PA, 1990.

9. Westbrook, C. K.; Dryer, F. L., Chemical Kinetics Modeling of Hydrocarbon Combustion, Prog. Energy Combust. Sci. 1984, 10, 1- 57.

10. Simmie, J. M., Detailed Chemical Kinetic Models for the Combustion of Hydrocarbon Fuels, Prog. Energy Combust. Sci. 2003, 29, 599- 634.

11. Battin-Leclerc, F., Detailed Chemical Kinetic Models for the Low-Temperature Combustion of Hydrocarbons with Application to Gaseous and Diesel Fuel Surrogates, Prog. Energy Combust. Sci. 2008, 34, 440- 498.

12. Burke, S. M.; Metcalfe, W.; Herbinet, O.; Battin-Leclerc, F.; Haas, F. M.; Santner, J.; Dryer, F. L.; Curran, H. J., An Experimental and Modeling Study of Propene Oxidation. Part I: Speciation Measurements in Jet-Stirred and Flow Reactors, Combust. Flame 2014, 161, 2765- 2784. 
13. Burke, S. M.; Burke, U.; McDonagh, R.; Mathieu, O.; Osorio, I.; Keesee, C.; Morones, A.; Petersen, E. L.; Wang, W.; DeVerter, T. A., An Experimental and Modeling Study of Propene Combustion. Part II: Ignition Delay Time and Flame Speed Measurements, Combust. Flame 2015, 162, 296- 314.

14. Zhang, Y.; Cai, J.; Zhao, L.; Yang, J.; Jin, H.; Cheng, Z.; Li, Y.; Zhang, L.; Qi, F., An Experimental and Kinetic Modeling Study of Three Butene Isomers Pyrolysis at Low Pressure, Combust. Flame 2012, 159, 905- 916.

15. Minetti, R.; Roubaud, A.; Therssen, E.; Ribaucour, M.; Sochet, L. R., The Chemistry of Pre-ignition of $n$-pentane and 1-pentene, Combust. Flame 1999, 118, 213- 220.

16. Ribaucour, M.; Minetti, R.; Sochet, L. R., Autoignition of $n$-Pentane and 1-Pentene: Experimental Data and Kinetic Modeling, Proc. Combust. Inst. 1998, 27, 345- 351.

17. Touchard, S.; Buda, F.; Dayma, G.; Glaude, P.-A.; Fournet, R.; Battin-Leclerc, F., Experimental and Modeling Study of the Oxidation of 1-Pentene at High Temperature, Int. J. Chem. Kinet. 2005, 37, 451- 463.

18. Touchard, S.; Fournet, R.; Glaude, P.-A.; Warth, V.; Battin-Leclerc, F.; Vanhove, G.; Ribaucour, M.; Minetti, R., Modeling of the Oxidation of Large Alkenes at Low Temperature, Proc. Combust. Inst. 2005, 30, $1073-1081$.

19. Gonzalo Alatorre, G.; Bohm, H.; Atakan, B.; Kohse-Hoinghaus, K., Experimental and Modelling Study of 1pentene Combustion at Fuel-Rich Conditions, Zeitsch Phys. Chem. 2001, 215, 981- 995.

20. Leppard, W. R., A Comparison of Olefin and Paraffin Autoignition Chemistries: A Motored Engine Study, SAE Paper 892081, SAE: Warrendale, PA, 1989.

21. Leppard, W. R., The Autoignition Chemistry of Primary Reference Fuels, Olefin/Paraffin Binary Mixtures, and Non Linear Octane Blending, SAE Paper 922325, SAE: Warrendale, PA, 1991.

22. Prabhu, S. K.; Bhat, R. K.; Miller, D. L.; Cernansky, N. P., 1-Pentene Oxidation and Its Interaction with Nitric Oxide in the Low and Negative Temperature Coefficient Regions, Combust. Flame 1996, 104, 377- 390.

23. Yahyaoui, M.; Djebaili-Chaumeix, N.; Pailliard, C.-E.; Touchard, S.; Fournet, R.; Glaude, P.-A.; Battin-Leclerc, F., Experimental and Modeling Study of 1-hexene Oxidation Behind Reflected Shock Waves, Proc. Combust. Inst. $2005,30,1137-1145$.

24. Yahyaoui, M.; Djebaili-Chaumeix, N.; Dagaut, P.; Pailliard, C.-E.; Gail, S., Kinetics of 1-hexene Oxidation in a JSR and a Shock Tube: Experimental and Modeling Study, Combust. Flame 2006, 147, 67- 78.

25. Vanhove, G.; Minetti, R.; Touchard, S.; Fournet, R.; Glaude, P.-A.; Battin-Leclerc, F., Experimental and Modeling Study of the Autoignition of 1-hexene/iso-octane Mixtures at Low Temperatures, Combust. Flame 2006, 145, 272- 281.

26. Battin-Leclerc, F.; Rodriguez, A.; Husson, B.; Herbinet, O.; Glaude, P.-A.; Wang, Z.; Cheng, Z.; Qi, F., Products from the Oxidation of Linear Isomers of Hexene, J. Phys. Chem. A 2014, 118, 673- 683.

27. Vanhove, G.; Ribaucour, M.; Minetti, R., On the Influence of the Position of the Double Bond on the LowTemperature Chemistry of Hexenes, Proc. Combust. Inst. 2005, 30, 1065- 1072.

28. Bounaceur, R.; Warth, V.; Sirjean, B.; Glaude, P.-A.; Fournet, R.; Battin-Leclerc, F., Influence of the Position of the Double Bond on the Autoignition of Linear Alkenes at Low Temperature, Proc. Combust. Inst. 2009, 32, 387- 394.

29. Mehl, M.; Vanhove, G.; Pitz, W. J.; Ranzi, E., Oxidation and Combustion of the $n$-hexene Isomers: A Wide Range Kinetic Modeling Study, Combust. Flame 2008, 155, 756- 772. 
30. Tanaka, S.; Ayala, F.; Keck, J. C.; Heywood, J. B., Two-Stage Ignition in HCCl Combustion and HCCl Control by Fuels and Additives, Combust. Flame 2003, 132, 219- 239.

31. Zhang, Y.; Yang, Y.; Boehman, A. L., Premixed Ignition Behavior of C9 Fatty Acid Esters: A Motored Engine Study, Combust. Flame 2009, 156, 1202- 1213.

32. Herbinet, O.; Pitz, W. J.; Westbrook, C. K., Detailed Chemical Kinetic Mechanism for the Oxidation of Biodiesel Fuels Blend Surrogate, Combust. Flame 2010, 157, 893- 908.

33. Wang, W.; Gowdagiri, S.; Oehlschlaeger, M. A., Comparative Study of the Autoignition of Methyl decanoates, Unsaturated Biodiesel Surrogates, Energy Fuels 2013, 27, 5527- 5532.

34. Metcalfe, W. K.; Pitz, W. J.; Curran, H. J.; Simmie, J. M.; Westbrook, C. K., The Development of a Detailed Chemical Kinetic Mechanism for Diisobutylene and Comparison to Shock Tube Ignition Times, Proc. Combust. Inst. 2007, 31, 377-384.

35. Goldsmith, C. F.; Klippenstein, S. J.; Green, W. H., Theoretical Rate Coefficients for allyl $+\mathrm{HO}_{2}$ and Allyloxy Decomposition, Proc. Combust. Inst. 2011, 33, 273- 282.

36. Mehl, M.; Faravelli, T.; Giavazzi, F.; Ranzi, E.; Scorletti, P.; Tardani, A.; Terna, D., Detailed Chemistry Promotes Understanding of Octane Numbers and Gasoline Sensitivity, Energy Fuels 2006, 20, 2391- 2398.

37. Curran, H. J.; Gaffuri, P.; Pitz, W. J.; Westbrook, C. K., A Comprehensive Modeling Study of $n$-Heptane Oxidation, Combust. Flame 1998, 114, 149- 177.

38. Fridlyand, A.; Goldsborough, S. S.; Brezinsky, K.; Merchant, S. S., Influence of the Double Bond Position on the Oxidation of Decene Isomers at High Pressures and Temperatures, Proc. Combust. Inst. 2015, 35, 333- 340.

39. Pitz, W. J.; Westbrook, C. K.; Leppard, W. R., Autoignition Chemistry of $C_{4}$ Olefins Under Motored Engine Conditions: A Comparison of Experimental and Modeling Results, SAE Paper 912315, SAE: Warrendale, PA, 1991.

40. Stark, M. S.; Waddington, R. W., Oxidation of Propene in the Gas Phase, Int. J. Chem. Kinet. 1995, 27, 123151.

41. Aul, C. J.; Metcalfe, W. K.; Burke, S. M.; Curran, H. J.; Petersen, E. L., Ignition and Kinetic Modeling of Methane and Ethane Fuel Blends with Oxygen: A Design of Experiments Approach, Combust. Flame 2013, 160, $1153-1167$. 42. Petersen, E. L.; Rickard, M. J. A.; Crofton, M. W.; Abbey, E. D.; Traum, M. J.; Kalitan, D. M., A Facility for Gasand Condensed-Phase Measurements Behind Shock Waves, Meas. Sci. Technol. 2005, 16, 1716- 1729.

43. Gauthier, B. M.; Davidson, D. F.; Hanson, R. K., Shock Tube Determination of Ignition Delay Times in FullBlend and Surrogate Fuel Mixtures, Combust. Flame 2004, 139, 300- 311.

44. Fikri, M.; Herzler, J.; Starke, R.; Schulz, C.; Roth, P.; Kalghatgi, G. T., Autoignition of Gasoline Surrogates Mixtures at Intermediate Temperatures and High Pressures, Combust. Flame 2008, 152, 276- 281.

45. Yahyaoui, M.; Djebaili-Chaumeix, N.; Dagaut, P.; Paillard, C.-E.; Gail, S., Experimental and Modelling Study of Gasoline Surrogate Mixtures Oxidation in Jet Stirred Reactor and Shock Tube, Proc. Combust. Inst. 2007, 31, 385- 391 .

46. Herbinet, O.; Battin-Leclerc, F., Progress in Understanding Low-Temperature Organic Compound Oxididation Using a Jet-Stirred Reactor, Int. J. Chem. Kinet. 2014, 46, 619- 139. 
47. Bahrini, C.; Morajkar, P.; Schoemaecker, C.; Frottier, O.; Herbinet, O.; Glaude, P.-A.; Battin-Leclerc, F.; Fittschen, C., Experimental and Modeling Study of the oxidation of $n$-butane in a jet stirred reactor using $\mathrm{cw}$ CRDS measurements, Phys. Chem. Chem. Phys. 2013, 15, 19686- 19698.

48. NIST 08, NIST/EPA/NIH Mass Spectral Library, http://www.sisweb.com/software/ms/nist.htm, July 2008.

49. Tranchant, J.; Gardais, J. F.; Gorin, P.; Serpinet, J.; Untz, G., Manuel Pratique De Chromatographie en Phase Gazeuse; Editions Masson, Paris, 1982.

50. Ribaucour, M.; Minetti, R.; Sochet, L. R.; Curran, H. J.; Pitz, W. J.; Westbrook, C. K., Ignition of Isomers of Pentane: An Experimental and Kinetic Modeling Study, Proc. Combust. Inst. 2000, 28, 1671- 1678.

51. Bugler, J.; Marks, B.; Mathieu, O.; Gregoire, C.; Archuleta, R.; Heufer, K. A.; Petersen, E. L.; Curran, H. J., manuscript in preparation, 2015.

52. Bugler, J.; Somers, K. P.; Silke, E. J.; Curran, H. J., Revisiting the Kinetics and Thermodynamics of the LowTemperature Oxidation Pathways of Alkanes: A Case Study of the Three Pentane Isomers, J. Phys. Chem. A 2015, DOI: 10.1021/acs.jpca.5b00837.

53. Curran, H. J.; Pitz, W. J.; Westbrook, C. K.; Hisham, M. W. M.; Walker, R. W., An Intermediate Temperature Modeling Study of the Combustion of Neopentane, Proc. Combust. Inst. 1996, 26, 641- 649.

54. Curran, H. J.; Gaffuri, P.; Pitz, W. J.; Westbrook, C. K., A Comprehensive Modeling Study of iso-Octane Oxidation, Combust. Flame 2002, 129, 253- 280.

55. Westbrook, C. K.; Pitz, W. J.; Curran, H. J., Chemical Kinetic Modeling Study of the Effects of Oxygenated Hydrocarbons on Soot Emissions from Diesel Engines, J. Phys. Chem. A 2006, 110, 6912- 6922.

56. Metcalfe, W. K.; Burke, S. M.; Ahmed, S. S.; Curran, H. J., A Hierarchical and Comparative Kinetic Modeling Study of $C_{1}-C_{2}$ Hydrocarbon and Oxygenated Fuels, Int. J. Chem. Kinet. 2013, 45, 638- 675.

57. Glaude, P.-A. Unpublished EXGAS mechanism, 2014.

58. CHEMKIN-PRO, release 15131; Reaction Design, Inc.: San Diego, 2013.

59. Brocard, J. C.; Baronnet, F.; O’Neal, H. E., Chemical Kinetics of the Oxidation of Methyl Tert-Butyl Ether (MTBE), Combust. Flame 1983, 52, 25- 35.

60. Lee, J.; Bozzelli, J. W., Thermochemical and Kinetic Analysis of the Allyl Radical with $\mathrm{O}_{2}$ Reaction System, Proc. Combust. Inst. 2005, 30, 1015- 1022.

61. Stothard, N. D.; Walker, R. W., Oxidation Chemistry of Propene in the Autoignition Region: Arrhenius Parameters for the Allyl $+\mathrm{O}_{2}$ Reaction Pathways and Kinetic Data for Initiation Reactions, J. Chem. Soc. Faraday Trans. 1992, 88, 2621- 2629.

62. Hall, J. M.; Petersen, E. L., An Optimized Kinetics Model for $\mathrm{OH}$ Chemiluminescence at High Temperatures and Atmospheric Pressures, Int. J. Chem. Kinet. 2006, 38, 714- 724.

63. Warnatz, J., The Structure of Laminar Alkane-, Alkene- and Acetylene Flames, Proc. Combust. Inst. 1980, 18, 369- 384 .

64. Westbrook, C. K.; Dryer, F. L., Prediction of Laminar Flame Properties of Methanol-Air Mixtures, Combust. Flame 1980, 37, 171- 192.

65. Westbrook, C. K., Chemical Kinetics of Hydrocarbon Ignition in Practical Combustion Systems, Proc. Combust. Inst. 2000, 28, 1563- 1577. 